\title{
Integrative taxonomy identifies two new tardigrade species (Eutardigrada: Macrobiotidae) from Greenland
}

\author{
Daniel STEC ${ }^{1, *}$, Denis V. TUMANOV ${ }^{2} \&$ Reinhardt Møbjerg KRISTENSEN ${ }^{3}$ \\ ${ }^{1}$ Institute of Zoology and Biomedical Research, Jagiellonian University, \\ Gronostajowa 9, 30-387 Kraków, Poland. \\ ${ }^{2}$ Department of Invertebrate Zoology, Faculty of Biology, \\ Saint-Petersburg State University, St. Petersburg, 199034, Russia. \\ ${ }^{3}$ Natural History Museum of Denmark, University of Copenhagen, \\ Universitetsparken 15, DK-2100 Copenhagen, Denmark. \\ ${ }^{*}$ Corresponding author: daniel stec@interia.eu \\ ${ }^{2}$ Email: d.tumanov@spbu.ru \\ ${ }^{3}$ Email: rmkristensen@snm.ku.dk \\ *urn:lsid:zoobank.org:author:13C435F8-25AB-47DE-B5BB-8CE788E92CF6 \\ ${ }^{2}$ urn:lsid:zoobank.org:author:49E22A70-C27B-485B-941E-577666EE65F9 \\ ${ }^{3}$ urn:lsid:zoobank.org:author:4BA89040-D79E-41C1-A17C-539FBB9B6BA4
}

\begin{abstract}
In this paper we describe Macrobiotus engbergi sp. nov. and Tenuibiotus zandrae sp. nov. from Greenland. Our study has involved both classical taxonomic methods, which include morphological and morphometric analyses conducted with the use of light and scanning electron microscopy, and genetic analysis based on four molecular markers (three nuclear: 18S rRNA, 28S rRNA, ITS-2, and one mitochondrial: COI). Moreover, we re-examined the type series of Tenuibiotus voronkovi (Tumanov, 2007) as well as the original sample where the species was found and we provide new morphological data from light and scanning electron microscopy which enabled us to amend its description. Finally, we also analysed slides with animals and egg of two populations from Nordaustlandet and Edgeøya (archipelago of Svalbard, Norway) designated as T. voronkovi within its recent redescription. The results and comparisons presented in our study question the validity of this designation.
\end{abstract}

Keywords. Arctic, egg ornamentation, Macrobiotus hufelandi complex, Tardigrada, Tenuibiotus voronkovi.

Stec D., Tumanov D.V. \& Kristensen R.M. 2020. Integrative taxonomy identifies two new tardigrade species (Eutardigrada: Macrobiotidae) from Greenland. European Journal of Taxonomy 614: 1-40.

https://doi.org/10.5852/ejt.2020.614

\section{Introduction}

The phylum Tardigrada comprises nearly 1300 species and yet is considered as a poorly known group of micro-invertebrates (Guidetti \& Bertolani 2005; Degma \& Guidetti 2007; Degma et al. 2009-2019). 
Over a dozen new tardigrade species are described each year, thereby expanding our knowledge of their biodiversity (Michalczyk \& Kaczmarek 2013). These small animals have been found to live in a large variety of habitats throughout the world. Although the vast majority of them are found in mosses and lichens, the diversity of marine species is also very high (Nelson et al. 2015; Fontoura et al. 2017; Degma \& Guidetti 2018; Jørgensen et al. 2018; Møbjerg et al. 2018).

The limno-terrestrial tardigrade family Macrobiotidae, with 14 genera, is one of the most specious tardigrade taxon (Bertolani et al. 2014; Degma et al. 2009-2019). The great majority of the genera within this family have been erected from the genus Macrobiotus C.A.S. Schultze, 1834, which is considered to be the largest of all of the genera and still polyphyletic at the same time (Bertolani et al. 2014; Degma et al. 2009-2019). In this study we describe two new species within this family found in Greenland, from which one is classified within the genus Macrobiotus (specifically in the Macrobiotus hufelandi complex) and the second in the genus Tenuibiotus Pilato \& Lisi, 2011. Although 90 species have been recorded from Greenland to date, the Macrobiotus hufelandi complex sensu Kaczmarek \& Michalczyk (2017) and the genus Tenuibiotus were represented by only four species (Kaczmarek et al. 2016), namely: M. hufelandi C.A.S. Schultze, 1834, M. persimilis Binda \& Pilato, 1972, M. recens Cuénot, 1932 and T. willardi (Pilato, 1977). Notably, however, according to several studies, records of mentioned species of the $M$. hufelandi complex from this area can be considered dubious (Bertolani \& Rebecchi 1993; Bertolani et al. 2011a; Kaczmarek \& Michalczyk 2017). Moreover, Tenuibiotus willardi was recorded from Greenland twice, once by Grøngaard et al. (1990) and the second time by Maucci (1996), but the first record was partially questioned by Zawierucha et al. (2016a), who found that the specimens of Tenuibiotus studied by Grøngaard et al. (1990) and attributed to T. willardi had different numbers of macroplacoids (two and three respectively), which suggests that two separate species had been present in that population.

The new species descriptions in our study are provided by combining modern molecular techniques with classical morphometric and morphological methods in an integrative approach. It included phase and Nomarski contrast light microscopy and scanning electron microscopy observations, as well as DNA sequencing (three nuclear markers: 18S rRNA, 28S rRNA, ITS-2 and one mitochondrial marker $\mathrm{COI})$ in the multifaceted delineation of the new species. Additionally, we re-examined the type series of $T$. voronkovi (Tumanov, 2007) and the original sample in which this species was found, which allow us to provide new morphological data and amend the description. Finally, we also examined slides with animals and eggs from two populations used by Zawierucha et al. (2016a) to redescribe T. voronkovi and we question their designation in the light of new data obtained from the type population.

\section{Material and methods}

\section{Sample processing}

The two moss and lichen samples, in which the new species were discovered, were collected from Greenland. The first sample was collected in Alluitsup Paa, south coast of Greenland $\left(60^{\circ} 28^{\prime} 1.5^{\prime \prime} \mathrm{N}\right.$, $45^{\circ} 34^{\prime} 27.8^{\prime \prime} \mathrm{W}, 25 \mathrm{~m}$ a.s.1.) by Lars Engberg Hansen on the $24^{\text {th }}$ August 2014. The second sample was collected in Østerlien, Disko Island, western coast of Greenland $\left(69^{\circ} 15^{\prime} 17^{\prime \prime} \mathrm{N}, 53^{\circ} 30^{\prime} 46^{\prime \prime} \mathrm{W}, 30 \mathrm{~m}\right.$ a.s.1.) by Karen Bjerregaard and Kjeld Akaaraq Emil Mølgaard on the $2^{\text {nd }}$ September 2016. The material was stored within paper envelopes at room temperature.

The samples were examined for tardigrades using the protocol by Dastych (1980) with modifications described in detail in Stec et al. (2015). All specimens found within these samples were dead, rending laboratory culture impossible. In order to perform the taxonomic analysis, animals and eggs isolated from the samples were split into three groups destined for specific analyses: morphological analysis with contrast light microscopy, morphological analysis with scanning electron microscopy and DNA sequencing (for details please see the "Material examined" section provided for each description). 


\section{Microscopy and imaging}

Specimens for light microscopy were mounted on microscope slides in a small drop of Hoyer's medium and secured with a cover slip, following the protocol by Morek et al. (2016). Slides were examined under an Olympus BX53 light microscope with phase and Nomarski contrasts (together termed later as light contrast microscopy), associated with an Olympus DP74 digital camera. Subsequently, after mounting, the specimens in the medium slides were also checked under phase contrast microscopy for the presence of males and females in the studied populations, as the spermatozoa in testis and spermathecae are visible for several hours after mounting (Coughlan et al. 2019; Coughlan \& Stec 2019). In order to obtain clean and extended specimens for scanning electron microscopy, tardigrades were processed according to the protocol by Stec et al. (2015). In short, specimens were first subjected to a $60^{\circ} \mathrm{C}$ water bath for $30 \mathrm{mn}$ to obtain fully extended animals, next to a water/ethanol and an ethanol/acetone series, then to $\mathrm{CO}_{2}$ critical point drying and finally sputter coated with a thin layer of gold. Bucco-pharyngeal apparatuses were extracted following the protocol of Eibye-Jacobsen (2001) as modified by Gąsiorek et al. (2016). Specimens were examined under high vacuum in a Versa 3D DualBeam scanning electron microscope at the ATOMIN facility of the Jagiellonian University, Kraków, Poland. Moreover, one egg of Tenuibiotus voronkovi was examined under high vacuum in a MIRA3 LMU scanning electron microscope at the Centre for Molecular and Cell Technologies, St Petersburg State University (for details please see Comparative material section below). All figures were assembled in Corel Photo-Paint X6, ver. 16.4.1.1281. For structures that could not be satisfactorily focused in a single light microscope photograph, a stack of 2-6 images was taken with an equidistance of ca $0.2 \mu \mathrm{m}$ and assembled manually into a single deep-focus image in Corel Photo-Paint X6.

\section{Morphometrics and morphological nomenclature}

All measurements are given in micrometres $(\mu \mathrm{m})$. Sample size was adjusted following recommendations by Stec et al. (2016). Structures were measured only if their orientation was suitable. Body length was measured from the anterior extremity to the end of the body, excluding the hind legs. The terminology used to describe oral cavity armature and egg shell morphology follows Michalczyk \& Kaczmarek (2003) and Kaczmarek \& Michalczyk (2017). Macroplacoid length sequence is given according to Kaczmarek et al. (2014). Buccal tube length and the level of the stylet support insertion point were measured according to Pilato (1981). The $p t$ index is the ratio of the length of a given structure to the length of the buccal tube expressed as a percentage (Pilato 1981). All other measurements and nomenclature follow Kaczmarek \& Michalczyk (2017). Specifically, buccal tube width was measured as the external and internal diameter at the level of the stylet support insertion point. Heights of the claw branches were measured from the base of the claw (i.e., excluding the lunula) to the top of the branch, including accessory points. Distance between egg processes was measured as the shortest line connecting base edges of the two randomly chosen closest processes. Morphometric data were handled using the "Parachela" ver. 1.6 template available from the Tardigrada Register (Michalczyk \& Kaczmarek 2013). Raw morphometric data for each analysed species are provided as supplementary files (SM.01 and SM.02). Tardigrade taxonomy follows Guil et al. (2019).

\section{Additional comparative material}

For morphological comparison of our new Tenuibiotus species we used slides with animals and eggs from the type series of Tenuibiotus voronkovi. Moreover, the re-examination of the original sample in which this species was found resulted in the discovery of one more egg which has been observed in a scanning electron microscope. Additionally, we re-examined slides with animals and eggs attributed to T. voronkovi by Zawierucha et al. (2016a) of populations from two islands in the archipelago of Svalbard, Norway: Nordaustlandet and Edgeøya. For more collection details please see Zawierucha et al. (2013, 2016a, 2016b). 


\title{
Genotyping
}

The DNA was extracted from individual animals following a Chelex ${ }^{\circledR} 100$ resin (Bio-Rad) extraction method by Casquet et al. (2012) with modifications described in detail in Stec et al. (2015). We sequenced four DNA fragments: the small ribosome subunit (18S rRNA, nDNA), the large ribosome subunit (28S rRNA, nDNA), the internal transcribed spacer (ITS-2, nDNA), and the cytochrome oxidase subunit I (COI, mtDNA). All fragments were amplified and sequenced according to the protocols described in Stec et al. (2015); primers and original references for specific PCR programs are listed in Table 1. Sequencing products were read with the ABI 3130xl sequencer at the Molecular Ecology Lab, Institute of Environmental Sciences of Jagiellonian University, Kraków, Poland. Sequences were processed in BioEdit ver. 7.2.5 (Hall 1999) and submitted to GenBank.

\section{Comparative molecular analysis}

For molecular comparisons, all published sequences of the four above-mentioned markers for species of the hufelandi complex were downloaded from GenBank (Appendix 1). To compare sequences of the new Tenuibiotus species we used all sequences of T. voronkovi published by Zawierucha et al. (2016a). The sequences for the M. hufelandi complex and two Tenuibiotus species were aligned separately using the default settings (in the case of ITS-2 and COI) and the Q-INS-I method (in the case of ribosomal markers: 18S rRNA, 28S rRNA) of MAFFT ver. 7 (Katoh et al. 2002; Katoh \& Toh 2008) and manually checked against non-conservative alignments in BioEdit. Then, the aligned sequences were trimmed to: 763 (18S rRNA), 714 (28S rRNA), 395 (ITS-2) and 618 (COI) bp for the M. hufelandi complex and 999 (18S rRNA), 737 (28S rRNA), 376 (ITS-2) and 584 (COI) bp for two Tenuibiotus species. All COI sequences were translated into protein sequences in MEGA7 version 7.0 (Kumar et al. 2016) to check against pseudogenes. Uncorrected pairwise distances were calculated using MEGA7 and are provided as a supplementary file (SM.03).

\author{
Abbreviations \\ IZiBB = Institute of Zoology and Biomedical Research, Jagiellonian University, Gronostajowa 9, \\ 30-387, Kraków, Poland \\ $\mathrm{LCM}=$ light contrast microscopy \\ $\mathrm{NCM}=$ Nomarski contrast light microscopy \\ $\mathrm{PCM}=$ phase contrast light microscopy \\ SEM = scanning electron microscopy
}

\section{Results}

\author{
Phylum Tardigrada Doyère, 1840 \\ Class Eutardigrada Richters, 1926 \\ Order: Macrobiotoidea Guil et al., 2019 \\ Family Macrobiotidae Thulin, 1928 \\ Genus Macrobiotus C.A.S. Schultze, 1834
}

Macrobiotus engbergi $\mathrm{sp}$. nov. urn:1sid:zoobank.org:act:C592B357-37F6-4C92-B16A-C28EDB17A231

Figs $1-9$

\section{Etymology}

We take great pleasure in dedicating this new species to the friend of the third author, Lars Engberg Hansen, who is a teacher emeritus from Qeqertarsuaq and Alluitsup Paa in Greenland and is always happy to help with collecting samples of mosses and lichens for us. 

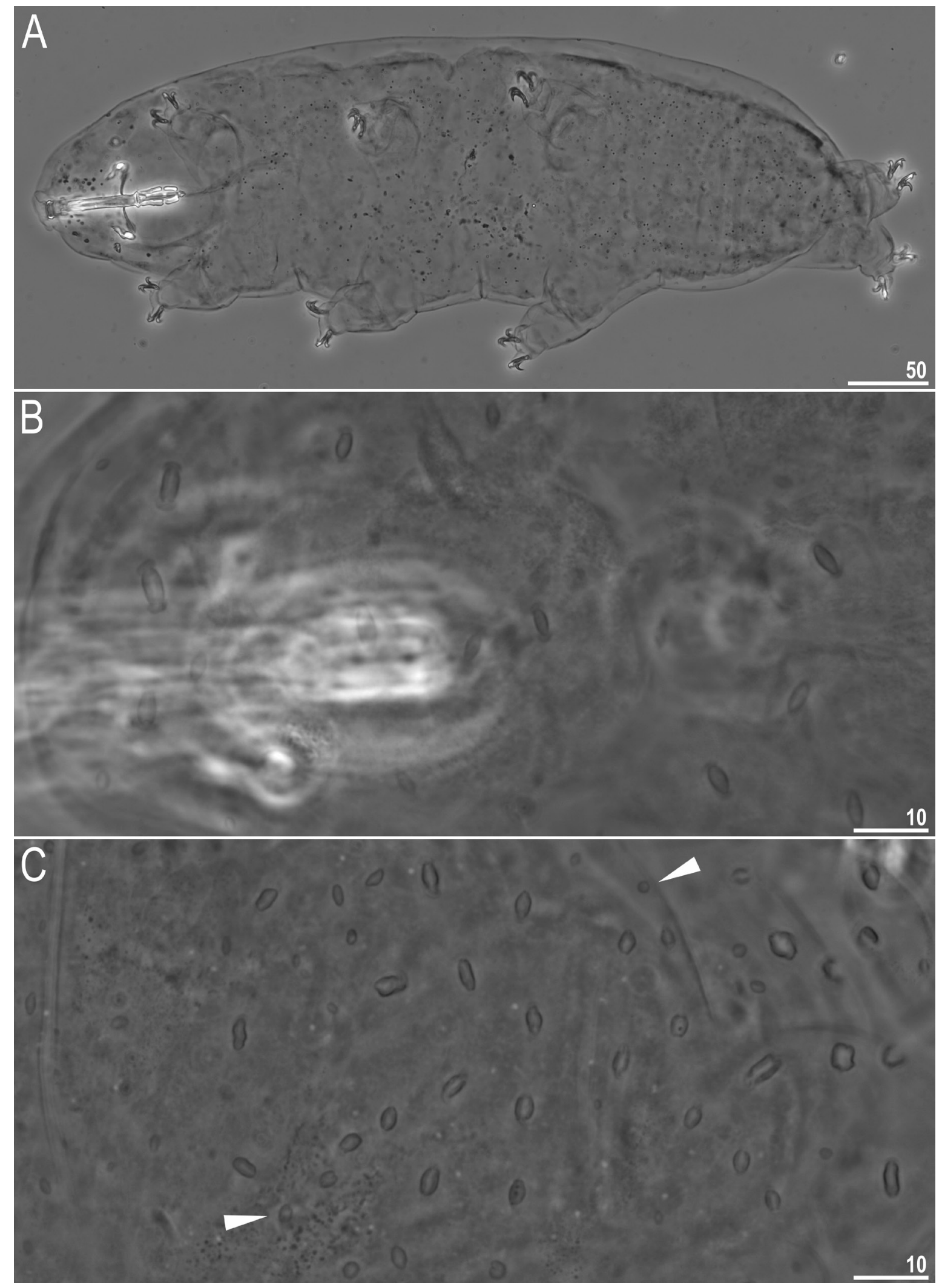

Fig. 1. Macrobiotus engbergi sp. nov. Habitus. A. Dorso-ventral projection (holotype, IZiBB, slide GL.052.22, Hoyer's medium, PCM). B-C. Cuticular pores on the dorso-cephalic and dorso-caudal part of the body seen in PCM, respectively. Arrowheads indicate small oval pores. Scale bars in $\mu \mathrm{m}$. 
Table 1. Primers and references for PCR protocols for amplification of the four DNA fragments sequenced in this study.

\begin{tabular}{|c|c|c|c|c|c|}
\hline $\begin{array}{c}\text { DNA } \\
\text { fragment }\end{array}$ & $\begin{array}{l}\text { Primer } \\
\text { name }\end{array}$ & $\begin{array}{c}\text { Primer } \\
\text { direction }\end{array}$ & Primer sequence $\left(5^{\prime}-3^{\prime}\right)$ & Primer source & $\begin{array}{c}\text { PCR } \\
\text { programme }\end{array}$ \\
\hline $18 \mathrm{~S}$ rRNA & $\begin{array}{l}\text { 18S_Tar_1Ff } \\
\text { 18S_Tar_1Rr }\end{array}$ & $\begin{array}{l}\text { forward } \\
\text { reverse }\end{array}$ & $\begin{array}{l}\text { AGGCGAAACCGCGAATGGCTC } \\
\text { GCCGCAGGCTCCACTCCTGG }\end{array}$ & Stec et al. (2017a) & Zeller (2010) \\
\hline 28S rRNA & $\begin{array}{l}\text { 28S_Eutar_F } \\
\text { 28SR0990 }\end{array}$ & $\begin{array}{l}\text { forward } \\
\text { reverse }\end{array}$ & $\begin{array}{l}\text { АCCCGCTGAACTTAAGCATAT } \\
\text { ССTTGGTCCGTGTTTCAAGAC }\end{array}$ & $\begin{array}{l}\text { Gąsiorek et al. } \\
\text { (2018), Mironov } \\
\text { et al. (2012) }\end{array}$ & $\begin{array}{l}\text { Mironov } \\
\text { et al. }(2012)\end{array}$ \\
\hline ITS-2 & $\begin{array}{l}\text { Eutar_Ff } \\
\text { Eutar_Rr }\end{array}$ & $\begin{array}{l}\text { forward } \\
\text { reverse }\end{array}$ & $\begin{array}{l}\text { CGTAACGTGAATTGCAGGAC } \\
\text { TCCTCCGCTTATTGATATGC }\end{array}$ & Stec et al. (2018a) & $\begin{array}{l}\text { Stec et al. } \\
\text { (2018a) }\end{array}$ \\
\hline COI & $\begin{array}{l}\text { LCO1490 } \\
\text { HCO2198 }\end{array}$ & $\begin{array}{l}\text { forward } \\
\text { reverse }\end{array}$ & $\begin{array}{l}\text { GGTCAACAAATCATAAAGATATTGG } \\
\text { TAAACTTCAGGGTGACCAAAAAATCA }\end{array}$ & $\begin{array}{l}\text { Folmer et al. } \\
\text { (1994) }\end{array}$ & $\begin{array}{l}\text { Michalczyk } \\
\text { et al. }(2012)\end{array}$ \\
\hline
\end{tabular}

\section{Material examined}

112 animals (including 9 simplex) and 108 eggs. Specimens mounted on microscope slides in Hoyer's medium (98 animals +103 eggs), fixed on SEM stubs $(10+5)$ and processed for DNA sequencing $(4+0)$.

\section{Holotype}

GREENLAND • ; ; Alluitsup Paa; 6028' $1.5^{\prime \prime} \mathrm{N}, 45^{\circ} 34^{\prime} 27.8^{\prime \prime} \mathrm{W} ; 25 \mathrm{~m}$ a.s.1.; mixed sample of moss and lichen collected from rock in arctic tundra; IZiBB, slide GL.052.22.

\section{Paratypes}

GREENLAND • 107 paratypes; same collection data as for holotype; IZiBB, slides GL.052.17 to 052.24, SEM stub 17.08 • 108 eggs; same collection data as for holotype; IZiBB, slides GL.052.09 to 052.16, SEM stub 17.08.
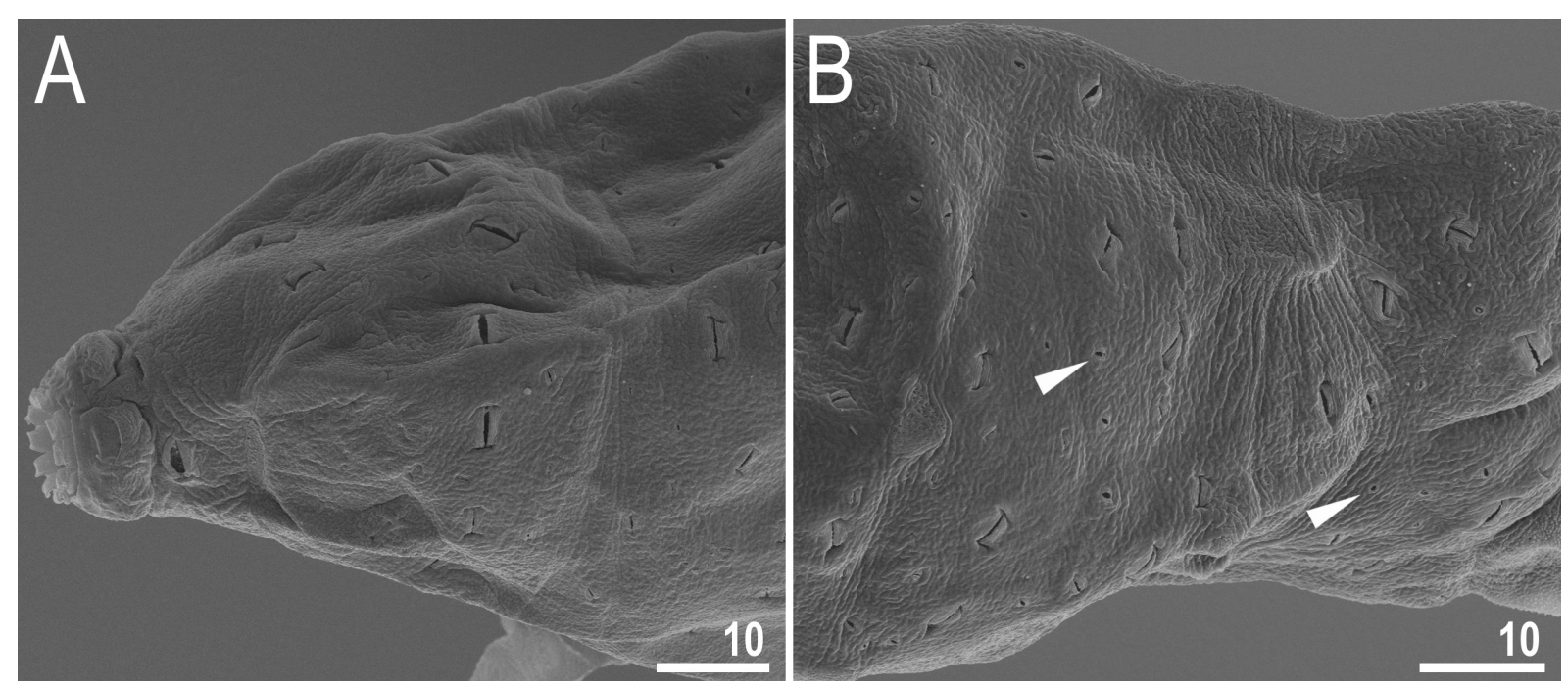

Fig. 2. Macrobiotus engbergi sp. nov. Cuticular pores (paratype). A-B. Cuticular pores on the dorsocephalic and dorso-caudal part of the body seen in SEM, respectively. Arrowheads indicate small oval pores Scale bars in $\mu \mathrm{m}$. 
STEC D. et al., Two new Macrobiotidae species from Greenland

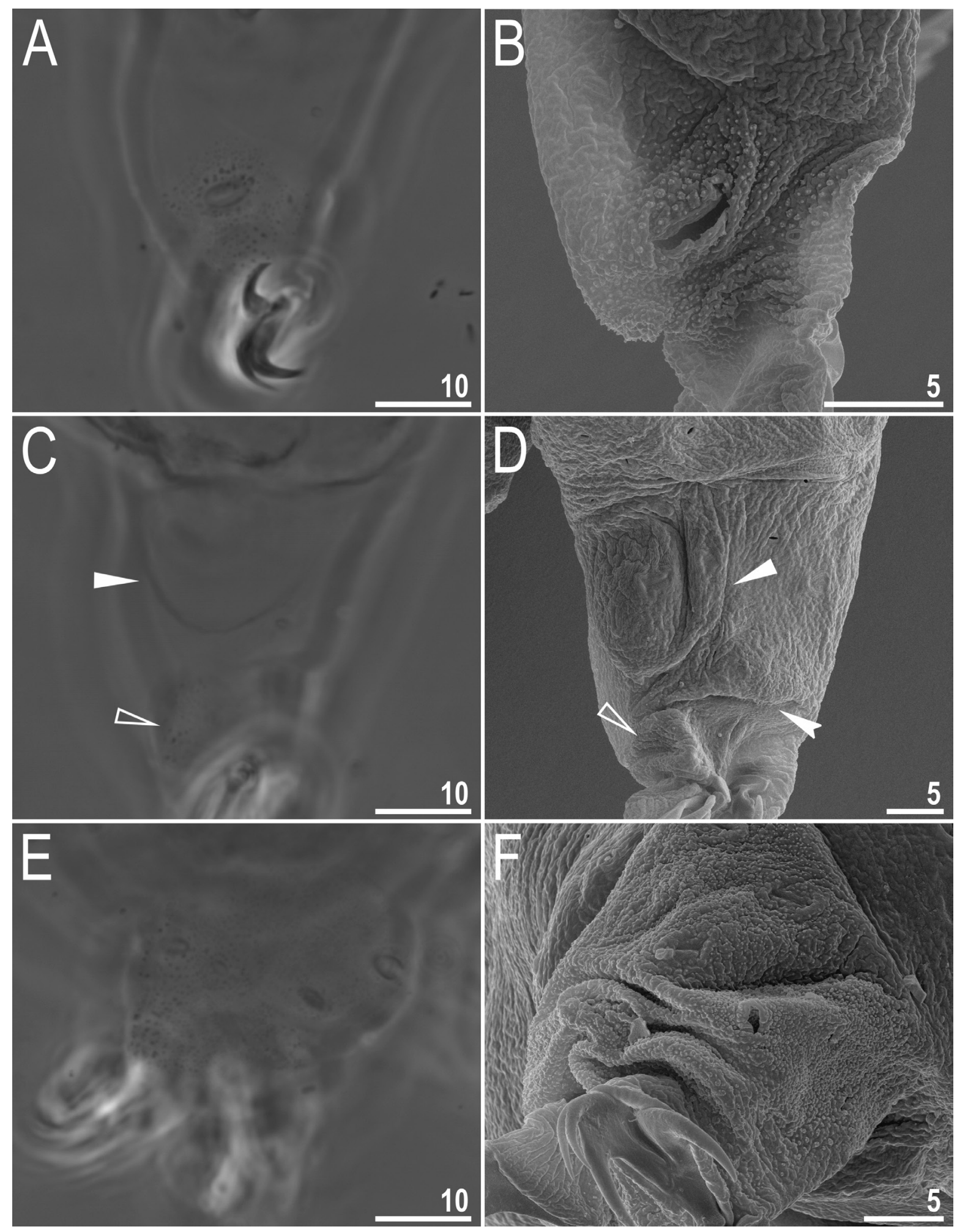

Fig. 3. Macrobiotus engbergi sp. nov. Cuticular structures on legs (paratypes). A-B. External granulation on leg III and II seen in PCM (A) and SEM (B), respectively. C-D. A cuticular bulge (pulvinus) and a faint cuticular fold, covered by granulation, on the internal surface of legs III seen in PCM (C) and SEM (D), respectively. E-F. Granulation on leg IV seen in PCM (E) and SEM (F). Filled flat arrowheads indicate the cuticular bulge, empty flat arrowheads indicate the faint cuticular fold under the claws whereas filled indented arrowhead indicate double muscle attachments under claws. Scale bars in $\mu \mathrm{m}$. 


\section{Description}

Animals (measurements and statistics in Table 2)

Body transparent in juveniles and whitish in adults, after fixation in Hoyer's medium transparent (Fig. 1A). Eyes present, visible also in specimens mounted in Hoyer's medium. Cuticle porous with two types of pores: large (up to $5.0 \mu \mathrm{m}$ in diameter) lenticular pores of shape resembling paper wrapped candy, with transversal wrinkles in extremities distributed randomly on entire body cuticle and being the biggest on anterior and posterior dorsal region (Figs 1B-C, 2); and small round cuticular pores $(0.3-0.7 \mu \mathrm{m}$ in diameter) scattered in between lenticular pores (Figs 1C, 2B). Patches of granulation on all legs present (Fig. 3). A patch of clearly visible granulation is present on the external surface of legs I-III (Fig. 3AB). A pulvinus present on internal surface of legs I-III, together with a faint cuticular fold covered with faint granulation and paired muscles attachments which are present just below claws (Fig. 3C-D). Both structures are visible only if the legs are fully extended and well oriented on slide. Granulation on legs IV always visible and consists of a single large granulation patch on each leg (Fig. 3E-F).
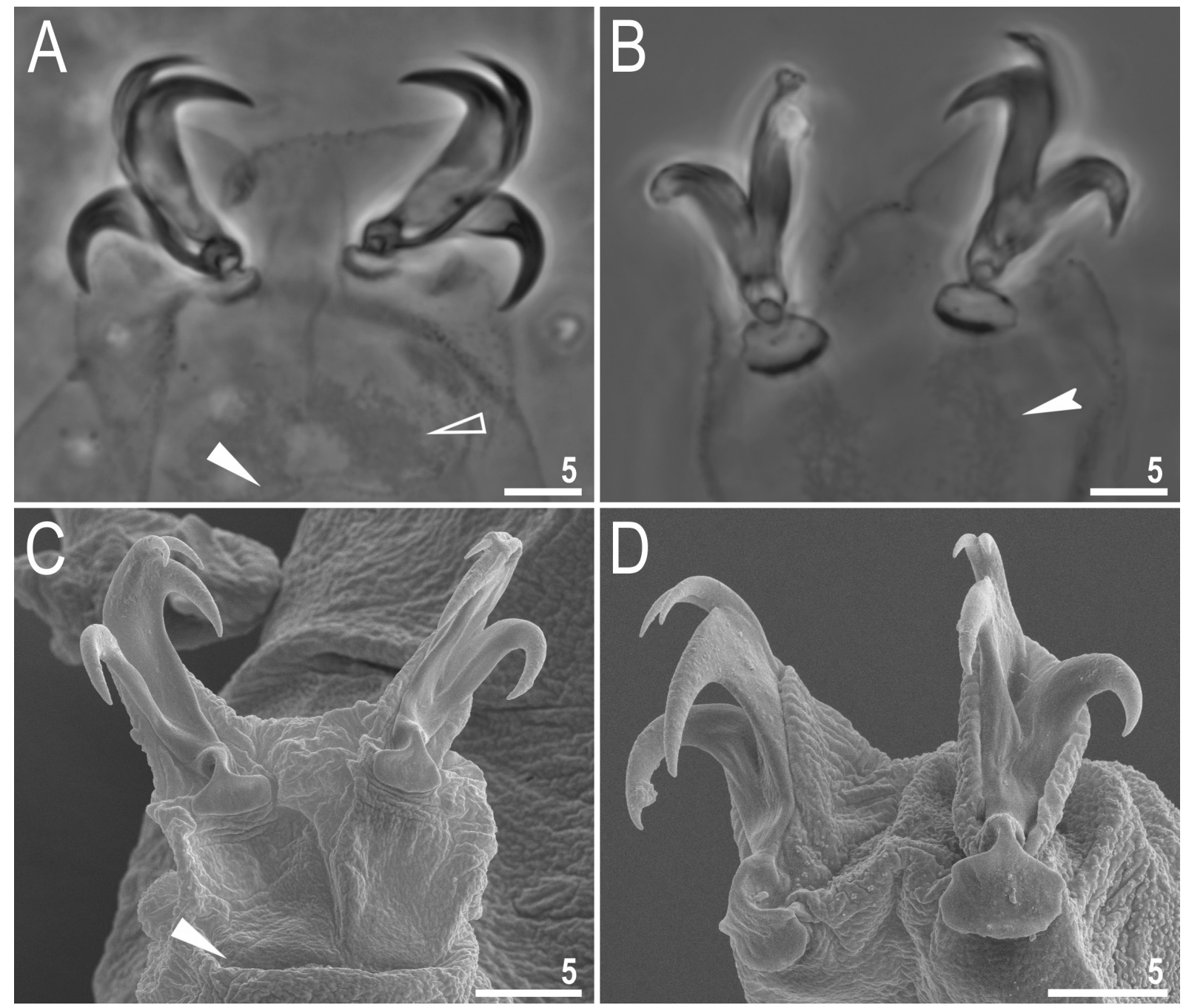

Fig. 4. Macrobiotus engbergi sp. nov. Claws (paratypes). A-B. Claws III and IV seen in PCM, respectively. C-D. Claws III and IV seen in SEM, respectively. Filled flat arrowheads indicate double muscles attachments under the claws, empty flat arrowhead indicates inverted horseshoe structure under the external and the internal claw, whereas filled indented arrowhead indicates horseshoe structure connecting the anterior and the posterior claw. Scale bars in $\mu \mathrm{m}$. 
STEC D. et al., Two new Macrobiotidae species from Greenland

Table 2. Measurements (in $\mu \mathrm{m}$ ) and $p t$ values of selected morphological structures of the holotype and paratypes of Macrobiotus engbergi sp. nov. mounted in Hoyer's medium. (N: number of specimens/ structures measured, RANGE refers to the smallest and the largest structure among all measured specimens; SD: standard deviation).

\begin{tabular}{|c|c|c|c|c|c|c|c|c|c|}
\hline \multirow{2}{*}{ Character } & \multirow{2}{*}{$\mathbf{N}$} & \multicolumn{2}{|c|}{ Range } & \multicolumn{2}{|c|}{ Mean } & \multicolumn{2}{|c|}{ SD } & \multicolumn{2}{|c|}{ Holotype } \\
\hline & & $\mu \mathrm{m}$ & $p t$ & $\mu \mathrm{m}$ & $p t$ & $\mu \mathrm{m}$ & $p t$ & $\mu \mathrm{m}$ & $p t$ \\
\hline Body length & 30 & $299-648$ & $861-1380$ & 517 & 1160 & 86 & 121 & 521 & 1089 \\
\hline \multicolumn{10}{|l|}{ Buccal tube } \\
\hline Length & 30 & $32.1-49.9$ & - & 44.3 & - & 4.3 & - & 47.8 & - \\
\hline Stylet support insertion point & 30 & $24.9-39.7$ & $77.0-79.9$ & 34.7 & 78.3 & 3.6 & 0.9 & 37.5 & 78.5 \\
\hline External width & 30 & $3.5-7.7$ & $10.9-16.0$ & 6.0 & 13.4 & 1.0 & 1.2 & 6.4 & 13.4 \\
\hline Internal width & 30 & $2.2-5.6$ & $6.9-11.6$ & 3.9 & 8.8 & 0.8 & 1.1 & 4.3 & 9.0 \\
\hline Ventral lamina length & 29 & $18.3-32.0$ & $54.2-66.4$ & 27.0 & 61.1 & 3.1 & 2.7 & 29.1 & 60.9 \\
\hline \multicolumn{10}{|l|}{ Placoid lengths } \\
\hline Macroplacoid 1 & 30 & $7.2-15.2$ & $22.4-31.5$ & 12.0 & 27.0 & 1.9 & 2.2 & 14.0 & 29.3 \\
\hline Macroplacoid 2 & 30 & $4.0-9.5$ & $12.5-19.6$ & 7.2 & 16.2 & 1.2 & 1.4 & 8.1 & 16.9 \\
\hline Microplacoid & 30 & $1.8-4.3$ & $5.6-8.9$ & 3.2 & 7.1 & 0.6 & 0.8 & 4.0 & 8.4 \\
\hline Macroplacoid row & 30 & $12.1-25.0$ & $37.7-51.6$ & 20.5 & 46.0 & 3.1 & 3.2 & 23.0 & 48.1 \\
\hline Placoid row & 30 & $15.6-29.8$ & $48.6-61.4$ & 24.5 & 55.2 & 3.5 & 3.2 & 28.2 & 59.0 \\
\hline \multicolumn{10}{|l|}{ Claw 1 heights } \\
\hline External primary branch & 27 & $7.7-15.5$ & $22.7-31.1$ & 12.1 & 27.0 & 1.7 & 2.0 & 12.8 & 26.8 \\
\hline External secondary branch & 22 & $5.9-12.4$ & $17.2-24.9$ & 9.2 & 20.7 & 1.4 & 1.8 & 10.1 & 21.1 \\
\hline Internal primary branch & 29 & $7.2-14.7$ & $22.2-29.6$ & 11.5 & 25.6 & 1.7 & 2.2 & 12.2 & 25.5 \\
\hline Internal secondary branch & 23 & $5.8-11.9$ & $16.9-23.9$ & 8.9 & 19.8 & 1.4 & 2.0 & 9.6 & 20.1 \\
\hline \multicolumn{10}{|l|}{ Claw 2 heights } \\
\hline External primary branch & 26 & $8.1-17.0$ & $23.0-34.1$ & 12.6 & 28.3 & 2.1 & 2.5 & 13.3 & 27.8 \\
\hline External secondary branch & 23 & $6.3-13.2$ & $17.2-26.5$ & 9.5 & 21.5 & 1.5 & 1.9 & 10.4 & 21.8 \\
\hline Internal primary branch & 28 & $7.6-16.0$ & $21.1-32.1$ & 12.0 & 27.0 & 2.0 & 2.5 & 12.6 & 26.4 \\
\hline Internal secondary branch & 22 & $6.3-12.1$ & $16.6-24.6$ & 9.4 & 20.9 & 1.5 & 2.2 & 9.4 & 19.7 \\
\hline \multicolumn{10}{|l|}{ Claw 3 heights } \\
\hline External primary branch & 29 & $8.0-15.4$ & $23.3-32.2$ & 12.6 & 28.4 & 1.9 & 2.3 & 13.4 & 28.0 \\
\hline External secondary branch & 24 & $6.3-11.8$ & $18.5-24.3$ & 9.6 & 21.8 & 1.3 & 1.6 & 10.4 & 21.8 \\
\hline Internal primary branch & 29 & $7.5-14.8$ & $21.6-30.6$ & 12.0 & 27.1 & 1.9 & 2.3 & 13.0 & 27.2 \\
\hline Internal secondary branch & 20 & $6.0-11.6$ & $17.3-24.0$ & 9.2 & 20.8 & 1.4 & 1.7 & 10.2 & 21.3 \\
\hline \multicolumn{10}{|l|}{ Claw 4 heights } \\
\hline Anterior primary branch & 25 & $8.8-18.4$ & $27.4-36.9$ & 14.6 & 32.7 & 2.1 & 2.5 & 15.6 & 32.6 \\
\hline Anterior secondary branch & 18 & $6.8-13.2$ & $19.6-27.0$ & 10.6 & 24.1 & 1.6 & 1.8 & 11.3 & 23.6 \\
\hline Posterior primary branch & 23 & $9.5-18.5$ & $29.6-38.2$ & 15.1 & 34.0 & 2.0 & 2.2 & 15.8 & 33.1 \\
\hline Posterior secondary branch & 18 & $7.2-12.8$ & $21.0-29.5$ & 11.1 & 25.5 & 1.6 & 2.0 & $?$ & $?$ \\
\hline
\end{tabular}

Claws stout, of the hufelandi type (Fig. 4). Primary branches with distinct accessory points, a common tract and with an evident stalk connecting the claw to the lunula (Fig. 4). Lunulae on all legs smooth (Fig. 4). Cuticular bars under claws are absent. Double muscle attachments are faintly marked under 
LCM but clearly visible under SEM (Fig. 4A, C). The horseshoe structure connecting the anterior and the posterior claw is present and is visible only in PCM (Fig. 4B) and sometimes also on legs I-III, but in this case inverted and not connecting the external and the internal claw (Fig. 4A).

Mouth antero-ventral, followed by ten peribuccal lamellae and a circular sensory lobe, surrounded by the ring of large pores (Figs 2A, 5A, 6). Bucco-pharyngeal apparatus of the Macrobiotus type
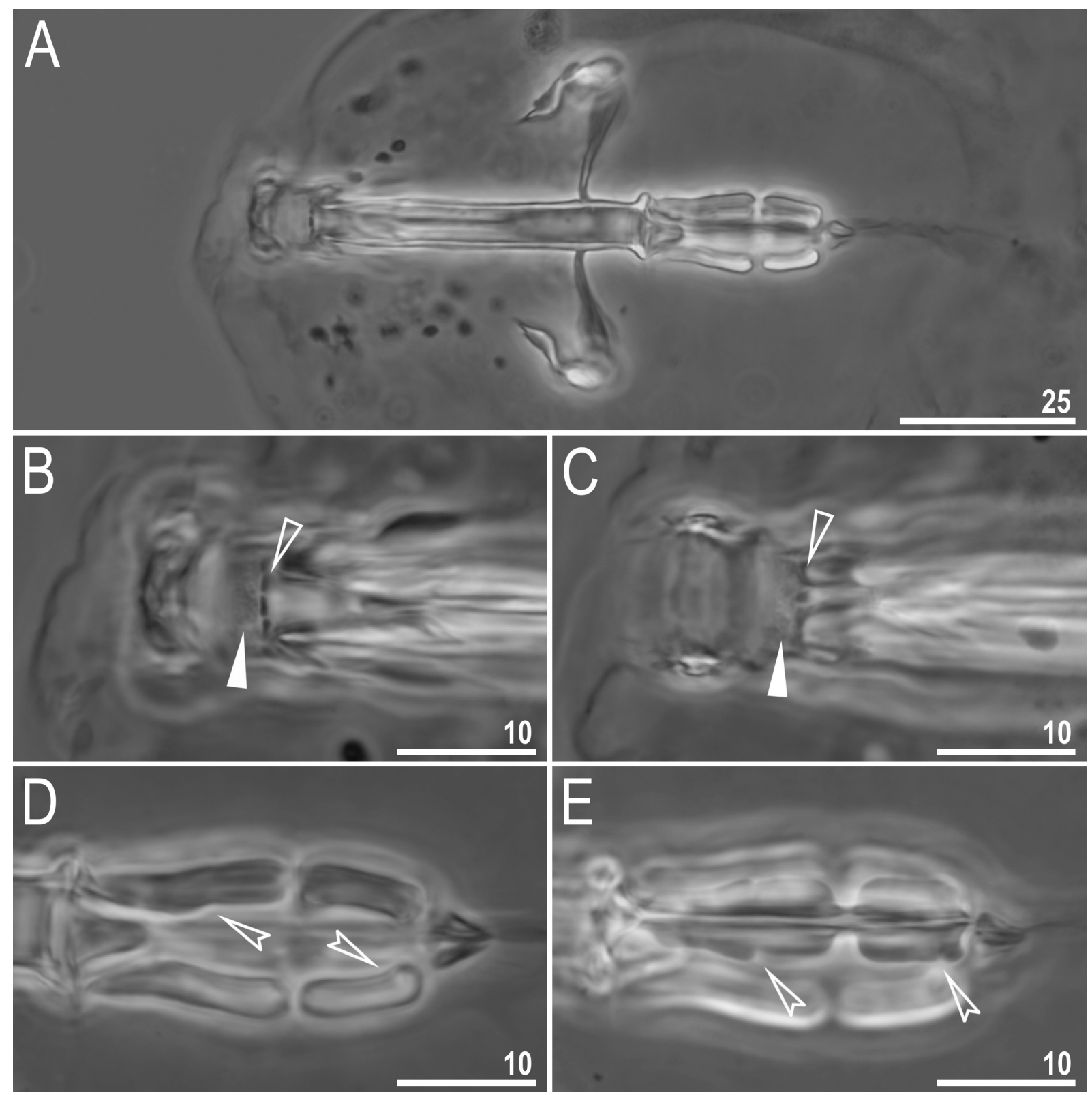

Fig. 5. Macrobiotus engbergi sp. nov. Buccal apparatus and the oral cavity armature seen in PCM (holotype, IZiBB, slide GL.052.22). A. Dorso-ventral projection of the entire buccal apparatus. B-C. Oral cavity armature visible in dorsal (B) and ventral (C) view, respectively. D-E. Placoid morphology visible in dorsal (D) and ventral (E) view, respectively. Filled flat arrowheads indicate the second band of teeth in the oral cavity, empty flat arrowheads indicate the third band of teeth in the oral cavity, empty indented arrowheads indicate central constrictions in the first macroplacoids and subterminal constriction in the second macroplacoids. Scale bars in $\mu \mathrm{m}$. 
(Fig. 5A). Under LCM, the oral cavity armature is of the patagonicus type, i.e., with only the $2^{\text {nd }}$ and $3^{\text {rd }}$ bands of teeth visible (Fig. 5B-C). However, in SEM all three bands of teeth are visible, with the first band situated at the base of peribuccal lamellae and composed of a 1-2 rows of small, cone-shaped teeth arranged around the oral cavity (Fig. 6). The second band of teeth is situated between the ring fold and the third band of teeth, and comprises 3-6 rows of small cone-shaped teeth (Figs 5B-C, 6). The teeth of the third band are located within the posterior portion of the oral cavity, between the second band of teeth and the buccal tube opening (Figs 5B-C, 6). The third band of teeth is discontinuous and divided into dorsal and ventral portions. Under LCM, the dorsal teeth are seen as three distinct transversal ridges, whereas the ventral teeth appear as two separate lateral transverse ridges and a median roundish tooth (Fig. 5B-C). In SEM, both dorsal and ventral teeth are also clearly distinct (Fig. 6). Under SEM, the margins of the dorsal teeth slightly serrated (Fig. 6A). Pharyngeal bulb spherical, with triangular apophyses, two rod-shaped macroplacoids and a small, triangular microplacoid (Fig. 5A, D-E). The macroplacoid length sequence $2<1$. The first macroplacoid has a central constriction, whereas the second macroplacoid is sub-terminally constricted (Fig. 5D-E).

Eggs (measurements and statistics in Table 3)

Laid freely, yellowish, spherical (Figs 7A, 8A). The surface between processes is of the persimilis type, i.e., with the continuous smooth chorion, never with pores or reticulum (Figs 7F-G, 8). Under PCM labyrinthine layer is visible as dark dots/thickenings on the surface between processes, whereas under SEM the surface is smooth (Figs $7 \mathrm{~F}-\mathrm{G}$ and 8 , respectively). Processes are of the inverted goblet shape, with slightly concave trunks and concave terminal discs (Figs 7B-C, 8A-C). Terminal discs are round with margins ranging from only serrated to clearly indented (Figs 7D-E, 8). Each terminal disc has a distinct concave central area, which may contain some scattered granulation within, and micro-granulations which are always present on the margins (visible only under SEM; Fig. 8C-D).
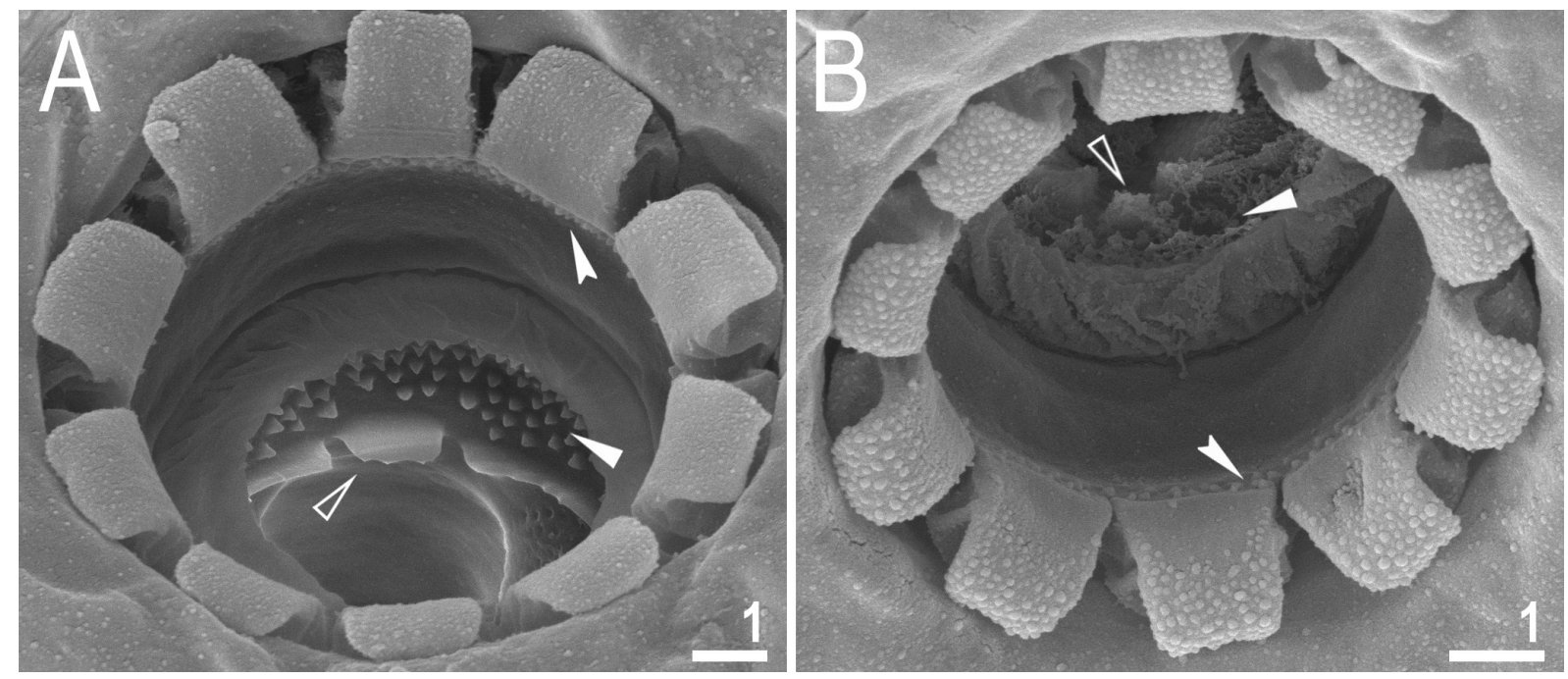

Fig. 6. Macrobiotus engbergi sp. nov. The oral cavity armature seen in SEM (paratypes). A-B. The oral cavity armature seen in SEM from different angles, dorsal (A) and ventral (B) view, respectively. Filled indented arrowheads indicate the first band of teeth in the oral cavity, filled flat arrowheads indicate the second band of teeth in the oral cavity whereas empty flat arrowheads indicate the third band of teeth in the oral cavity. Scale bars in $\mu \mathrm{m}$. 


\section{Reproduction}

The new species is dioecious. Spermathecae in females as well as testis in males have been found to be filled with spermatozoa, clearly visible under LCM up to 24 hours after mounting in Hoyer's medium. The new species exhibits a male secondary sexual dimorphism trait in the form of evident lateral gibbosities on legs IV (Fig. 9).

\section{DNA sequences}

We obtained sequences for all four of the above mentioned DNA markers. Sequences of $18 \mathrm{~S}$ rRNA and $28 \mathrm{~S}$ rRNA were represented by single haplotypes, whereas sequences of ITS-2 and COI were represented by two (distance: $0.5 \%$ ) and three (distance: $1.3-1.8 \%$ ) haplotypes, respectively:
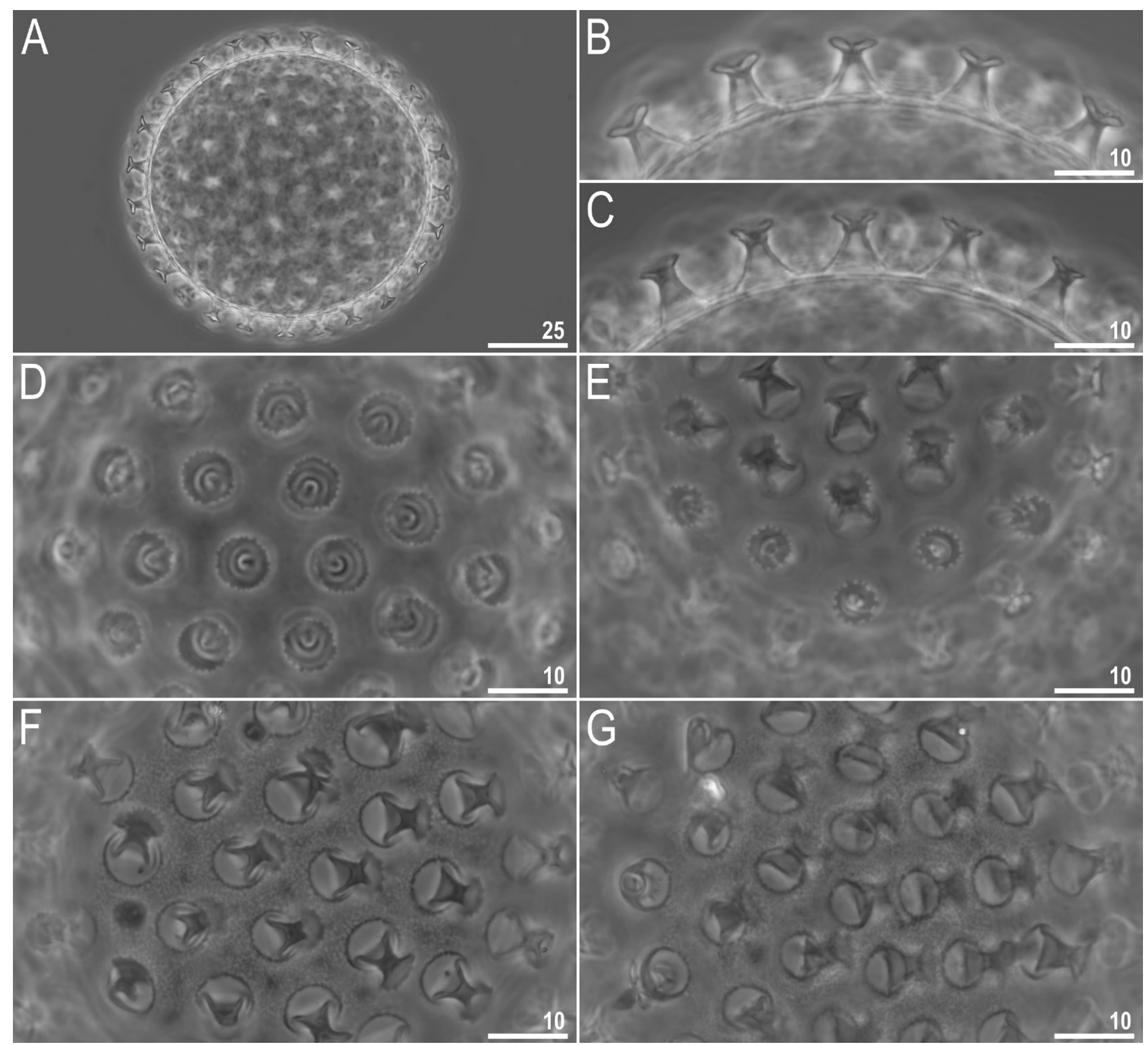

Fig. 7. Macrobiotus engbergi sp. nov. Egg chorion morphology seen in PCM. A. Midsection under $400 \times$ magnification. B-C. Midsection under 1000× magnification. D-E. Terminal discs under 1000× magnification. F-G. Surface under $1000 \times$ magnification. Scale bars in $\mu \mathrm{m}$. 
STEC D. et al., Two new Macrobiotidae species from Greenland

Table 3. Measurements (in $\mu \mathrm{m}$ ) of selected morphological structures of the eggs of Macrobiotus engbergi sp. nov. mounted in Hoyer's medium (N: number of eggs/structures measured; RANGE refers to the smallest and the largest structure among all measured specimens; SD: standard deviation).

\begin{tabular}{lcccc}
\hline CHARACTER & N & RANGE & MEAN & SD \\
\hline Egg bare diameter & 30 & $78.4-101.6$ & 87.9 & 6.0 \\
Egg full diameter & 30 & $88.7-115.8$ & 102.4 & 6.6 \\
Process height & 90 & $4.2-8.6$ & 6.9 & 1.0 \\
Process base width & 90 & $4.2-8.9$ & 6.3 & 0.9 \\
Process base/height ratio & 90 & $70-139 \%$ & $93 \%$ & $15 \%$ \\
Terminal disc width & 90 & $4.4-8.3$ & 6.0 & 0.9 \\
Inter-process distance & 90 & $2.2-5.4$ & 3.8 & 0.7 \\
Number of processes on the egg circumference & 30 & $21-28$ & 23.5 & 1.6 \\
\hline
\end{tabular}
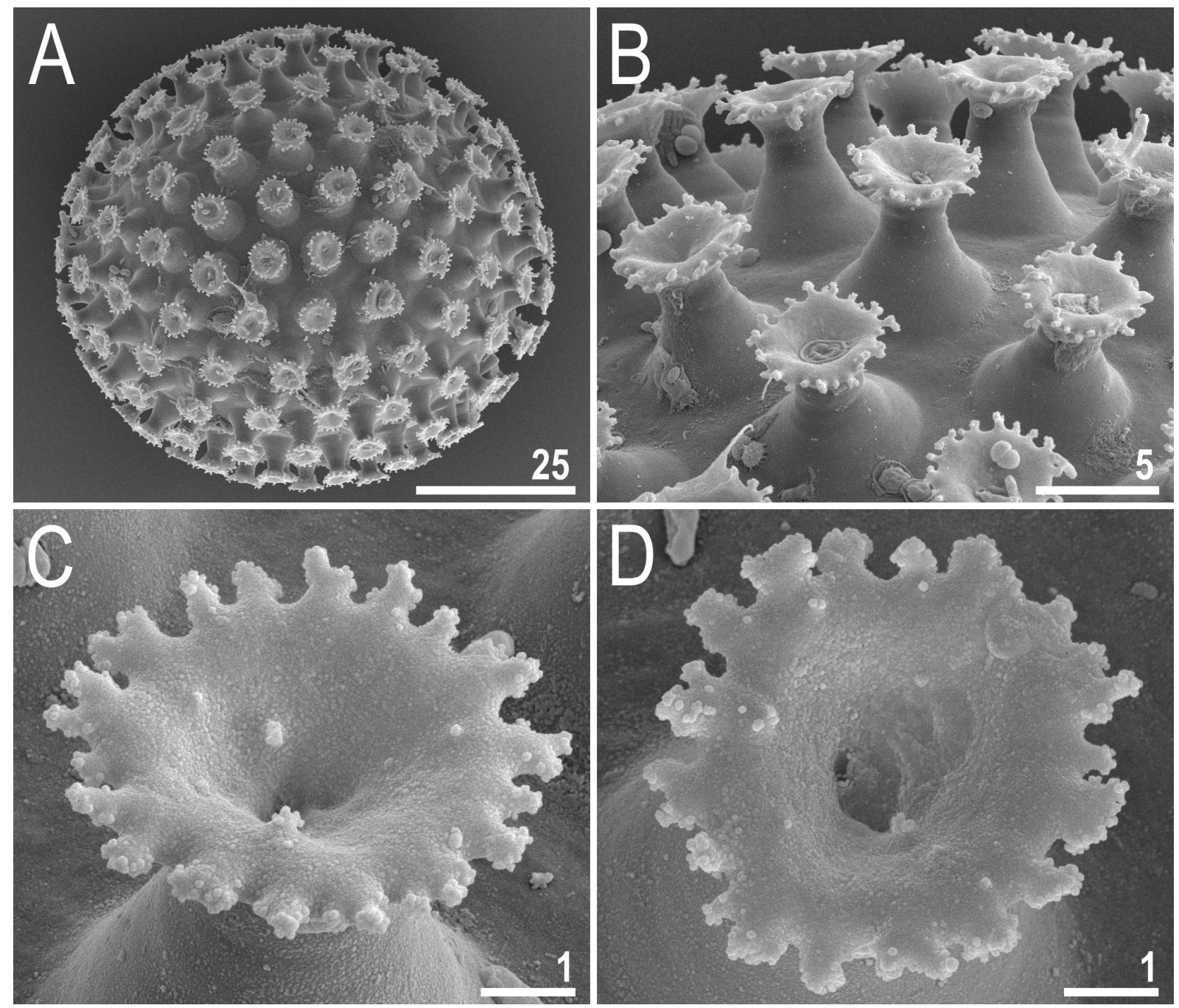

Fig. 8. Macrobiotus engbergi sp. nov. Egg chorion morphology seen in SEM. A. Entire egg. B. Magnification of the egg surface. C-D. Details of the terminal discs. Scale bars in $\mu \mathrm{m}$. 
18S rRNA sequence (GenBank: MN443039), 1017 bp long; 28S rRNA sequence (GenBank: MN443034), 783 bp long;

ITS-2 haplotype 1 sequence (GenBank: MN443036), 374 bp long; ITS-2 haplotype 2 sequence (GenBank: MN443037), 374 bp long; COI haplotype 1 sequence (GenBank: MN444824), 638 bp long; COI haplotype 2 sequence (GenBank: MN444825), 638 bp long; COI haplotype 3 sequence (GenBank: MN444826), 638 bp long.
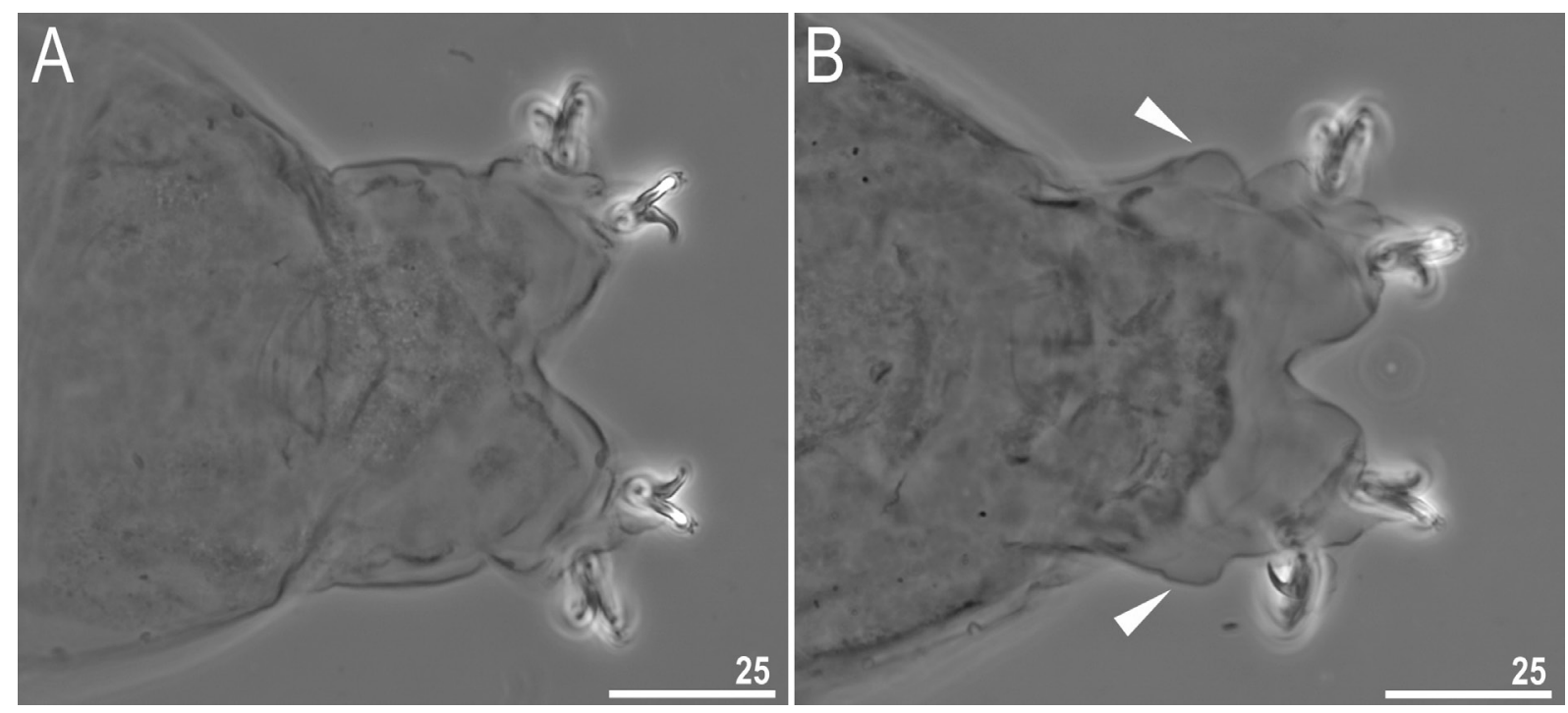

Fig. 9. Macrobiotus engbergi sp. nov. Secondary sexual dimorphism. A. Female without gibbosities on the hind legs. B. Male with gibbosities on the hind legs. Arrowheads indicate gibbosities. Scale bars in $\mu \mathrm{m}$.

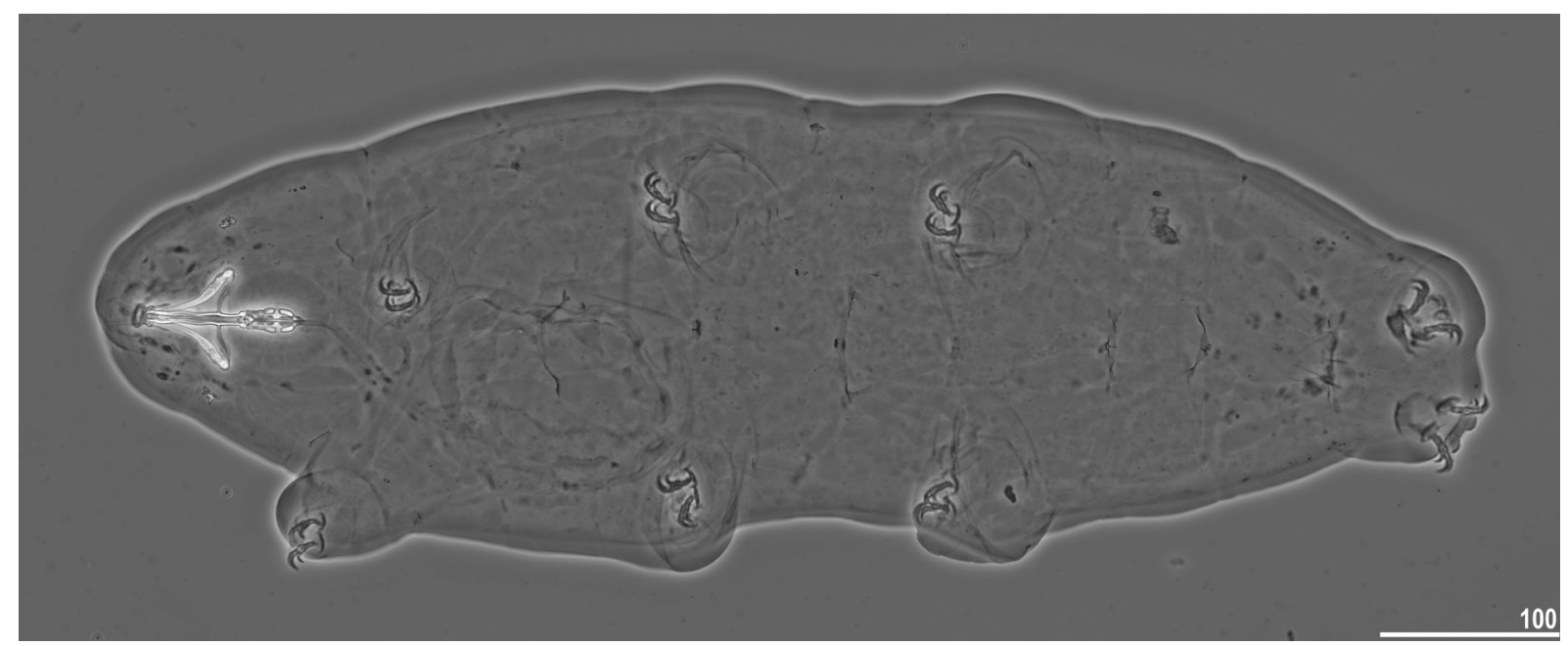

Fig. 10. Tenuibiotus zandrae sp. nov. Habitus. Dorso-ventral projection (holotype, IZiBB, slide GL.011.17, Hoyer's medium, PCM). Scale bars in $\mu \mathrm{m}$. 
STEC D. et al., Two new Macrobiotidae species from Greenland

Genus Tenuibiotus Pilato \& Lisi, 2011

Tenuibiotus zandrae sp. nov.

urn:1sid:zoobank.org:act:99D6163D-E8E6-4223-B975-F68AA2268304

Figs 10-19

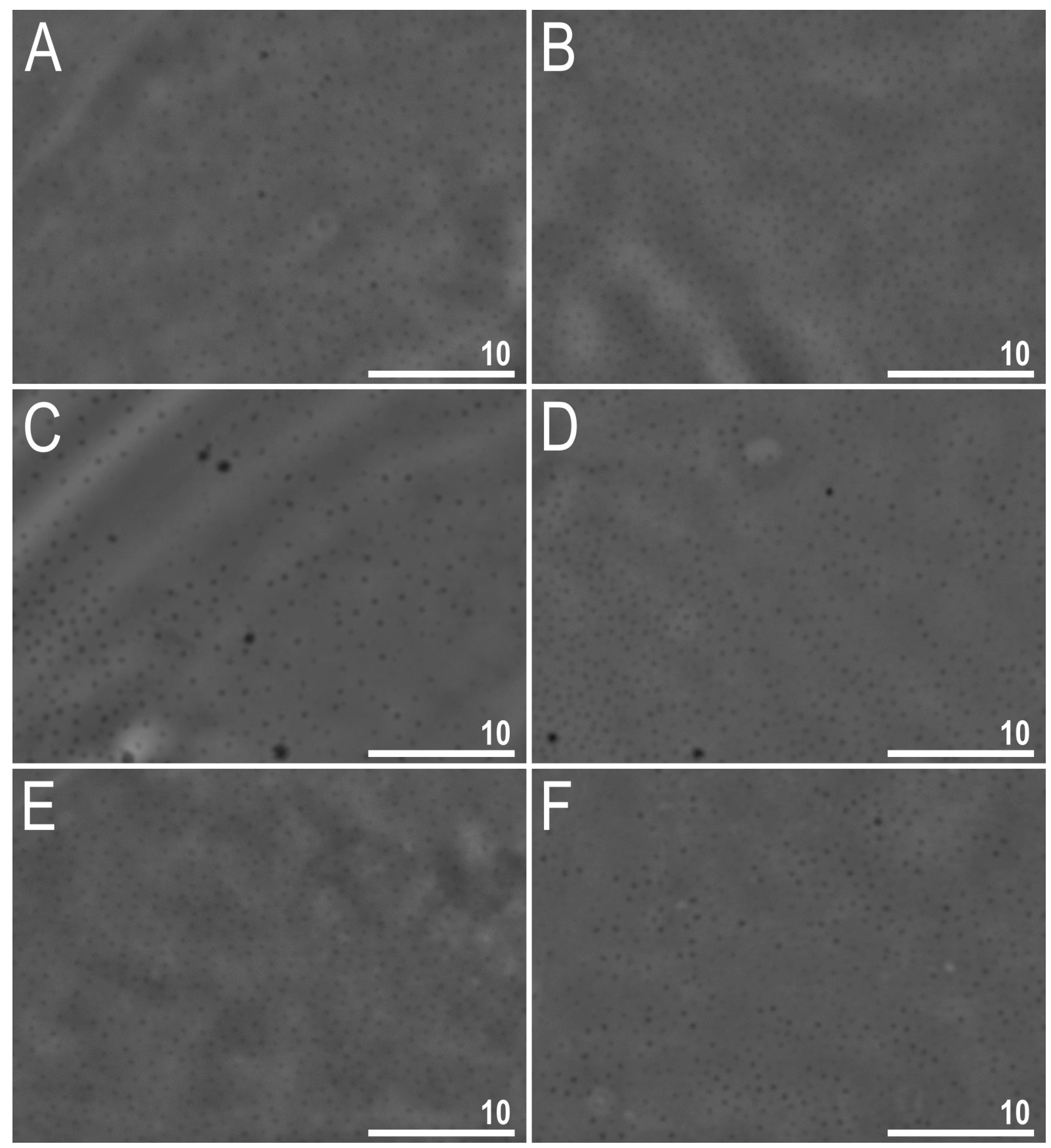

Fig. 11. Tenuibiotus zandrae sp. nov. Body granulation seen in PCM (paratypes). A-B. Uniformly distributed granulation on the dorso-cephalic and dorso-caudal part of the body. C-D. Uniformly distributed granulation on the dorso-cephalic and dorso-caudal part of the body with small, random patches of lacking granulation. $\mathbf{E}-\mathbf{F}$. Uniformly distributed granulation on the ventral side of the body without and with small random patches lacking granulation, respectively. A-B, E and C-D, F are from two different paratypes. Scale bars in $\mu \mathrm{m}$. 


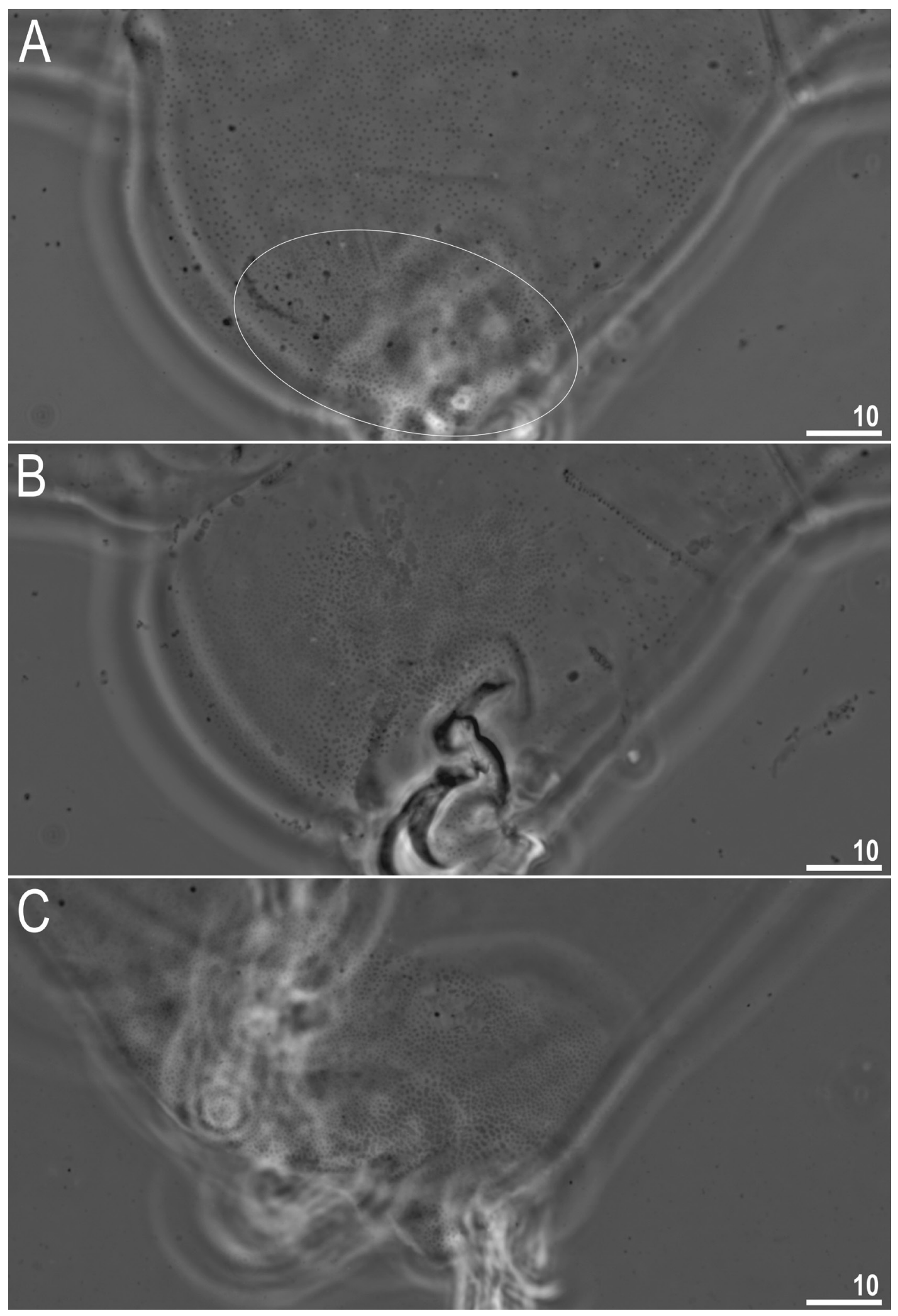

Fig. 12. Tenuibiotus zandrae sp. nov. Patches of dense granulation on legs seen in PCM (paratypes). A. External granulation on leg III (patch of dense granulation encircled). B. Internal granulation on leg III. C. Granulation on leg IV. Scale bars in $\mu \mathrm{m}$. 
STEC D. et al., Two new Macrobiotidae species from Greenland

\section{Etymology}

We take great pleasure in dedicating this new species to the friend of the first and third authors. Zandra Maria Skandrup Sigvardt, who recently completed her PhD studies working on crustaceans (Section of Biosystematics) at the Natural History Museum of Denmark in Copenhagen.

\section{Material examined}

62 animals (including 18 simplex) and 171 eggs. Specimens mounted on microscope slides in Hoyer's medium (49 animals +161 eggs), fixed on SEM stubs (including two extracted buccal apparatuses) $(10+10)$, and processed for DNA sequencing $(3+0)$.

\section{Holotype}

GREENLAND • Disko Island, Østerlien; 69 $9^{\circ} 5^{\prime} 17^{\prime \prime} \mathrm{N}, 53^{\circ} 30^{\prime} 46^{\prime \prime} \mathrm{W} ; 30 \mathrm{~m}$ a.s.1.; sample of moss collected from the rock in arctic tundra; IZiBB, slide GL.011.17.
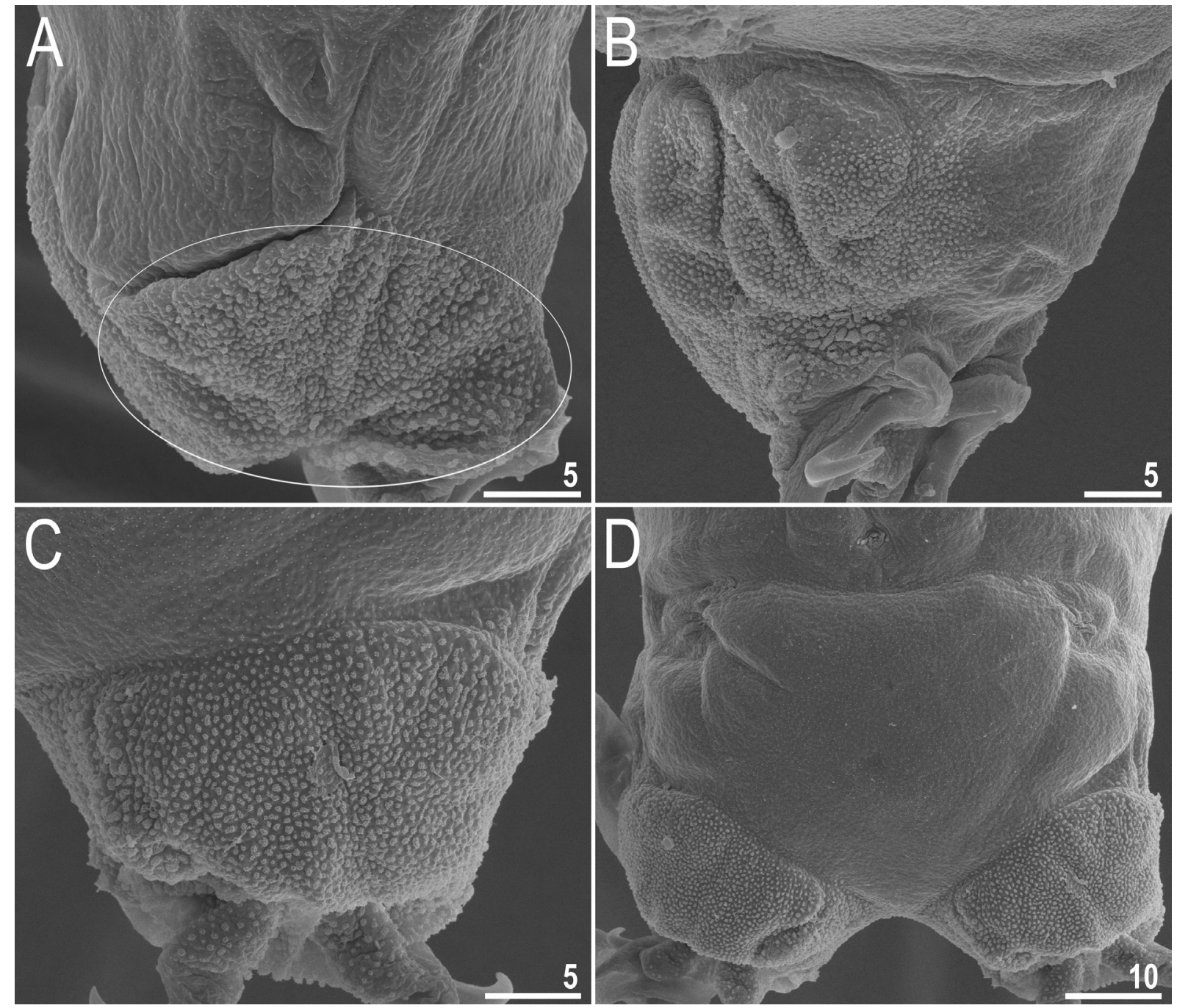

Fig. 13. Tenuibiotus zandrae sp. nov. Patches of dense granulation on legs seen in SEM (paratypes). A. External granulation on leg II (patch of dense granulation encircled). B. Internal granulation on leg III. C. Granulation on leg IV. D. Granulation on legs IV and uniformly distributed body granulation on the dorso-caudal region. Scale bars in $\mu \mathrm{m}$. 


\section{Paratypes}

GREENLAND - 58 paratypes; same collection data as for holotype; IZiBB, slides GL.011.08 to 011.09, 011.16 to $011.19,011.22$ to $011.23,011.27$ to 011.28 , SEM stubs GL.012.06 to $012.07,012.13 \cdot 171$ eggs; same collection data as for holotype; IZiBB, slides GL.011.10 to $011.15,011.20$ to $011.21,011.24$ to $011.26,011.29$, SEM stub GL.12.13.

\section{Description}

Animals (measurements and statistics in Table 4)

Body transparent in juveniles and whitish in adults, after fixation in Hoyer's medium transparent (Fig. 10). Eyes present in specimens mounted in Hoyer's medium. Body cuticle without pores but covered with fine granulation including ventral side of the body and all legs (Figs 11-13). Granulation is distributed uniformly on the body (Fig. 11A-B, E) but sometimes, especially in larger specimens, random patches without granulation are present on the body cuticle (Fig. 11C-D, F). Patches of dense granulation composed of cushions with aggregated granules present on all legs (Figs 12-13). A patch of

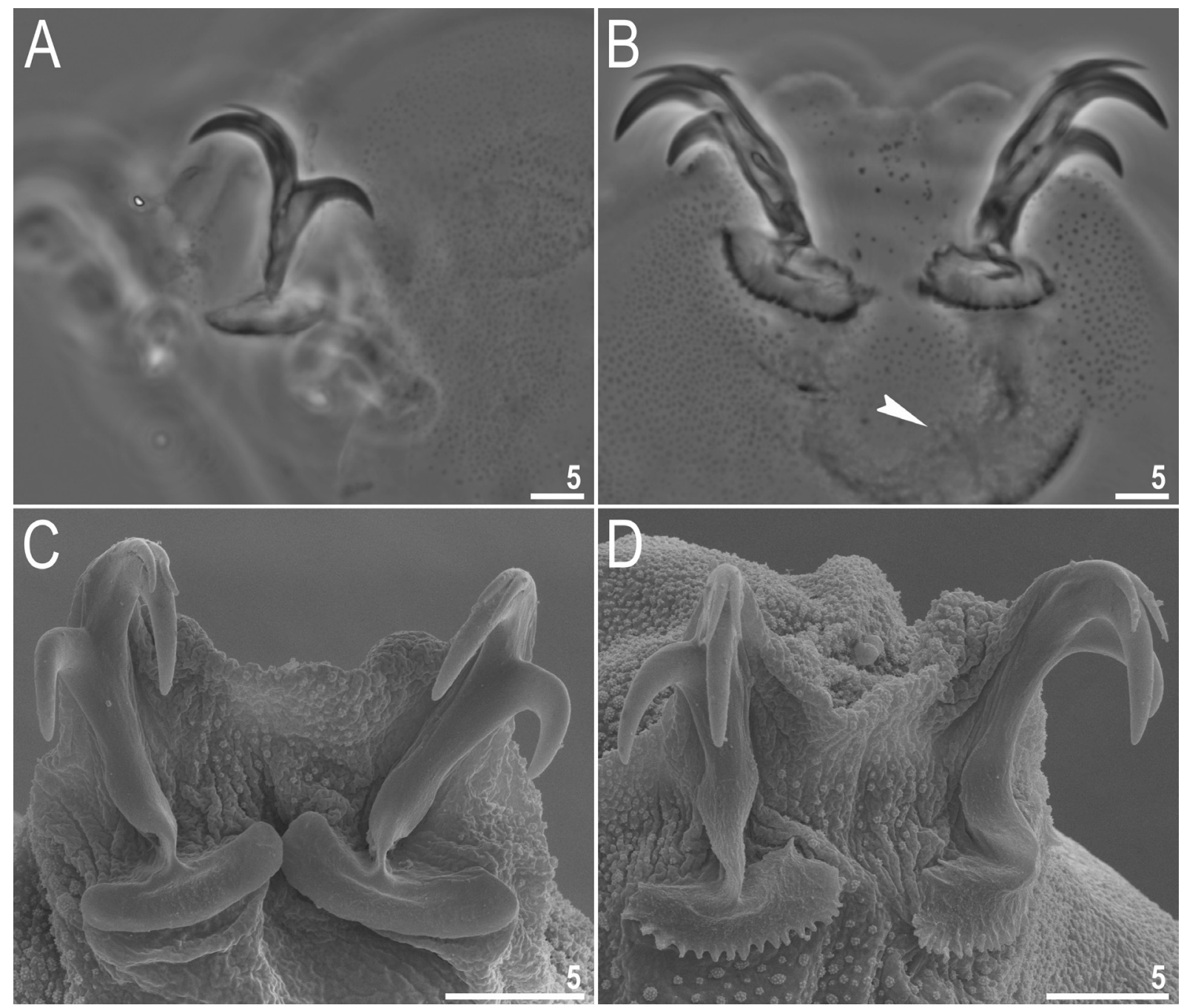

Fig. 14. Tenuibiotus zandrae sp. nov. Claws (paratypes). A-B. Claws II and IV seen in PCM, respectively. C-D. Claws I and IV seen in SEM, respectively. Filled indented arrowhead indicates horseshoe structure connecting the anterior and the posterior claw. Scale bars in $\mu \mathrm{m}$. 
STEC D. et al., Two new Macrobiotidae species from Greenland

Table 4. Measurements (in $\mu \mathrm{m}$ ) and $p t$ values of selected morphological structures of the holotype and paratypes of Tenuibiotus zandrae sp. nov. mounted in Hoyer's medium. (N: number of specimens/ structures measured; RANGE refers to the smallest and the largest structure among all measured specimens; SD: standard deviation).

\begin{tabular}{|c|c|c|c|c|c|c|c|c|c|}
\hline \multirow{2}{*}{ CHARACTER } & \multirow{2}{*}{$\mathbf{N}$} & \multicolumn{2}{|c|}{ RANGE } & \multicolumn{2}{|c|}{ MEAN } & \multicolumn{2}{|c|}{ SD } & \multicolumn{2}{|c|}{ Holotype } \\
\hline & & $\mu \mathrm{m}$ & $p t$ & $\mu \mathrm{m}$ & $p t$ & $\mu \mathrm{m}$ & $p t$ & $\mu \mathrm{m}$ & $p t$ \\
\hline Body length & 22 & $259-824$ & $830-1499$ & 573 & 1193 & 172 & 181 & 768 & 1383 \\
\hline \multicolumn{10}{|l|}{ Buccal tube } \\
\hline Length & 22 & $31.2-58.1$ & & 47.0 & - & 8.4 & - & 55.5 & - \\
\hline Stylet support insertion point & 22 & $22.7-41.5$ & $71.2-73.3$ & 34.0 & 72.3 & 6.0 & 0.7 & 40.0 & 72.1 \\
\hline External width & 22 & $3.3-7.7$ & $10.3-14.3$ & 5.9 & 12.4 & 1.4 & 1.0 & 7.4 & 13.3 \\
\hline Internal width & 22 & $1.8-5.2$ & 4.9-9.9 & 3.6 & 7.4 & 1.1 & 1.3 & 4.6 & 8.3 \\
\hline Ventral lamina length & 21 & $17.7-32.6$ & $54.1-58.9$ & 26.4 & 56.4 & 4.7 & 1.6 & 30.0 & 54.1 \\
\hline \multicolumn{10}{|l|}{ Placoid lengths } \\
\hline Macroplacoid 1 & 22 & $6.6-16.6$ & $18.7-30.9$ & 12.2 & 25.4 & 3.4 & 3.2 & 15.2 & 27.4 \\
\hline Macroplacoid 2 & 22 & $3.7-9.1$ & $11.7-16.4$ & 6.4 & 13.5 & 1.8 & 1.5 & 8.2 & 14.8 \\
\hline Microplacoid & 22 & $1.4-4.1$ & $4.1-7.4$ & 2.7 & 5.7 & 0.8 & 0.9 & 3.5 & 6.3 \\
\hline Macroplacoid row & 22 & $11.7-26.8$ & $33.9-49.9$ & 20.3 & 42.5 & 5.3 & 4.3 & 25.6 & 46.1 \\
\hline Placoid row & 22 & $14.0-31.5$ & $40.5-57.4$ & 23.9 & 50.1 & 6.2 & 4.8 & 30.1 & 54.2 \\
\hline \multicolumn{10}{|l|}{ Claw 1 heights } \\
\hline External primary branch & 17 & $9.1-18.4$ & $26.2-33.7$ & 14.0 & 30.2 & 3.3 & 2.5 & 18.2 & 32.8 \\
\hline External secondary branch & 9 & $6.3-13.7$ & $18.9-25.8$ & 10.5 & 22.6 & 2.9 & 2.2 & 12.8 & 23.1 \\
\hline Internal primary branch & 19 & $9.1-18.6$ & $24.2-33.4$ & 13.7 & 29.5 & 3.4 & 2.7 & 18.0 & 32.4 \\
\hline Internal secondary branch & 16 & $6.1-13.4$ & $18.4-25.2$ & 10.3 & 22.1 & 2.6 & 1.8 & 12.6 & 22.7 \\
\hline \multicolumn{10}{|l|}{ Claw 2 heights } \\
\hline External primary branch & 19 & $9.1-19.0$ & $28.3-35.4$ & 14.8 & 31.8 & 3.5 & 2.3 & 18.8 & 33.9 \\
\hline External secondary branch & 11 & $6.4-14.8$ & $20.3-27.6$ & 11.2 & 23.8 & 3.2 & 2.3 & 13.9 & 25.0 \\
\hline Internal primary branch & 19 & $9.1-18.6$ & $27.8-34.8$ & 14.8 & 31.4 & 3.2 & 2.2 & 17.7 & 31.9 \\
\hline Internal secondary branch & 17 & $6.9-13.9$ & $19.2-26.0$ & 10.8 & 22.9 & 2.5 & 1.7 & 13.0 & 23.4 \\
\hline \multicolumn{10}{|l|}{ Claw 3 heights } \\
\hline External primary branch & 19 & $9.2-19.6$ & $28.4-36.9$ & 15.2 & 32.7 & 3.7 & 2.7 & 18.9 & 34.1 \\
\hline External secondary branch & 13 & $7.0-15.1$ & $22.0-27.1$ & 11.9 & 24.8 & 2.9 & 1.7 & 14.4 & 25.9 \\
\hline Internal primary branch & 19 & $9.0-20.0$ & $26.3-36.2$ & 14.7 & 31.5 & 3.7 & 2.8 & 18.5 & 33.3 \\
\hline Internal secondary branch & 17 & $6.2-15.9$ & $18.0-28.5$ & 10.8 & 23.1 & 3.0 & 2.6 & 14.2 & 25.6 \\
\hline \multicolumn{10}{|l|}{ Claw 4 heights } \\
\hline Anterior primary branch & 18 & $10.3-22.5$ & $31.3-40.4$ & 17.1 & 36.0 & 3.7 & 2.8 & 21.6 & 38.9 \\
\hline Anterior secondary branch & 15 & $7.2-15.8$ & $21.7-29.4$ & 12.4 & 25.8 & 2.6 & 2.1 & 14.7 & 26.5 \\
\hline Posterior primary branch & 19 & $10.6-23.2$ & $33.3-41.7$ & 17.3 & 37.8 & 4.1 & 2.8 & 22.8 & 41.1 \\
\hline Posterior secondary branch & 18 & $7.1-17.0$ & $22.5-30.5$ & 12.4 & 26.8 & 3.0 & 2.2 & 15.9 & 28.6 \\
\hline
\end{tabular}

clearly visible granulation, is present on the external surface of legs I-III just below the claws (Figs 12A, $13 \mathrm{~A})$. A pulvinus is absent on the internal surface of legs I-III, whereas a patch of dense granulation is present and wider than the patch on the external leg surface (Figs 12B, 13B). A patch of dense granulation on legs IV is always visible and covers the dorsal and the lateral sides of hind legs (Figs 12C, 13C-D). 
Claws slender, of the Tenuibiotus type (Fig. 14). Primary branches with distinct accessory points, a long common tract, and with an evident stalk connecting the claw to the very wide lunula (Fig. 14). Lunulae I-III smooth (Fig. 14A, C), whereas lunulae IV exhibit clear dentation (Fig. 14B, D). The horseshoe structure connecting the anterior and the posterior claw is present and is visible only in PCM (Fig. 14B).

Mouth antero-ventral, followed by ten peribuccal lamellae (Figs 15A, 16). Bucco-pharyngeal apparatus of the Macrobiotus type (Figs 15A, 17A). Under LCM, only the second and third bands of teeth visible, with the second band being faintly marked (Fig. 15B-C). However, in SEM all
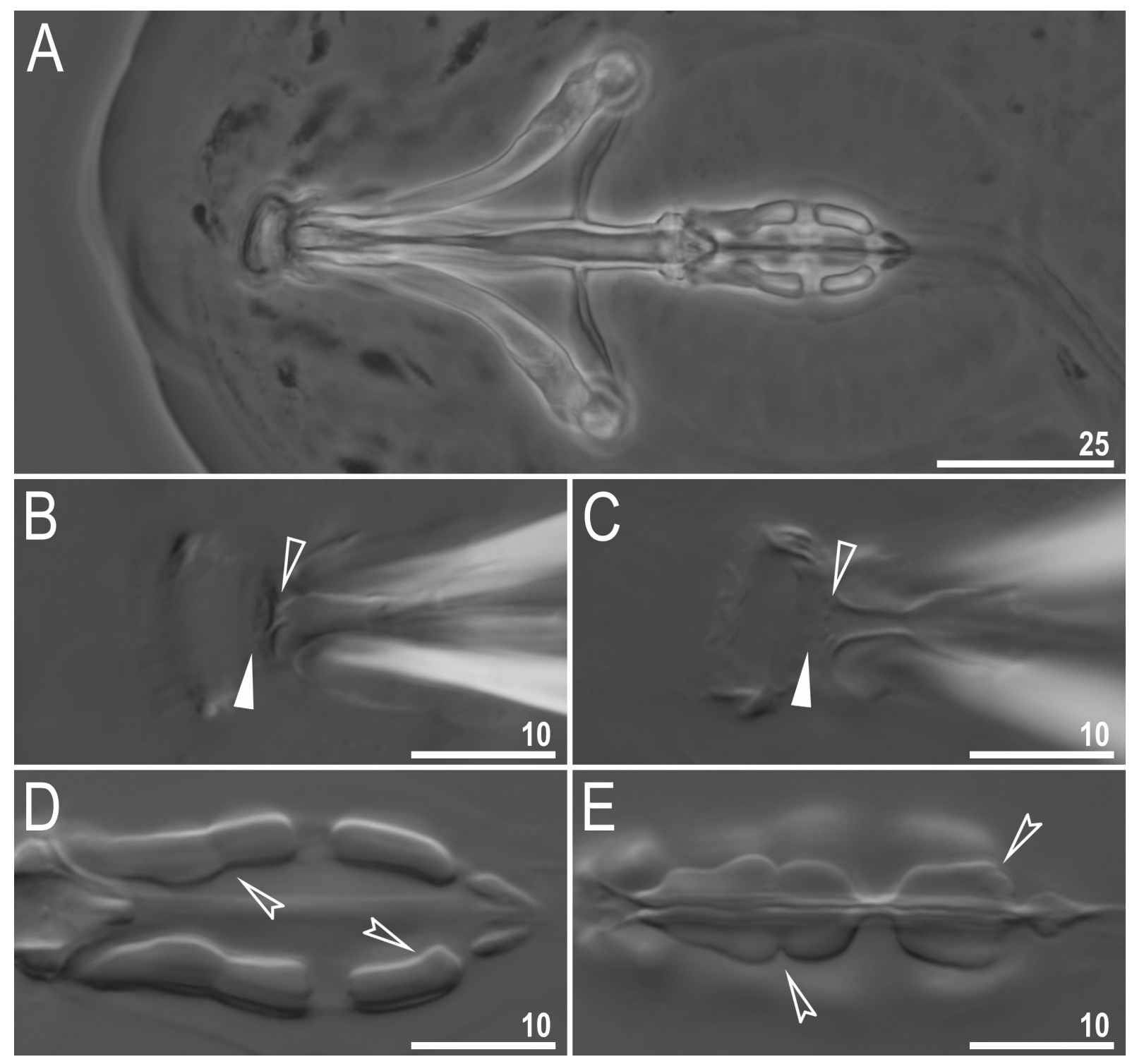

Fig. 15. Tenuibiotus zandrae sp. nov. Buccal apparatus and the oral cavity armature seen in LCM. A. Dorso-ventral projection of the entire buccal apparatus (holotype, IZiBB, slide GL.011.17, PCM). B-C. Oral cavity armature seen in NCM, dorsal (B, paratype) and ventral (C, holotype) view, respectively. D-E. Placoid morphology seen in NCM, dorsal (D) and ventral (E) view, respectively (both holotype). Filled flat arrowheads indicate faintly visible second band of teeth in the oral cavity, empty flat arrowheads indicate the third band of teeth in the oral cavity, empty indented arrowheads indicate central constrictions in the first macroplacoids and the subterminal constriction in the second macroplacoid. Scale bars in $\mu \mathrm{m}$. 
three bands of teeth are visible, with the first band being situated at the base of peribuccal lamellae and composed of 1-2 rows of small, cone-shaped teeth arranged around the oral cavity (Figs 16, 17B). The second band of teeth is situated between the ring fold and the third band of teeth and comprises 3-6 rows of small, cone-shaped teeth (Figs 15B-C, 16). The teeth of the third band are located within the posterior portion of the oral cavity, between the second band of teeth and the buccal tube opening (Figs 15B-C,16). The third band of teeth is discontinuous and divided into dorsal and ventral portions. Under LCM, the dorsal teeth are seen as three distinct transversal ridges of which the median tooth is triangular and is wedged between the lateral teeth (Fig. 15B). The ventral teeth under LCM appear as three to four separate roundish teeth, largest than those of the second band (Fig. 15C), only sometimes they can be seen as one faintly marked, elongated tooth. In SEM, both dorsal and ventral teeth are also clearly distinct (Fig. 16). Under SEM, the medio-dorsal tooth is the largest within the third band and is positioned anteriorly with respect to the lateral teeth (Fig. 16A), whereas the ventral portion consist of cone-shaped teeth of which the lateral ones are larger than the medial ones (Fig. 16B). Pharyngeal bulb spherical, with triangular apophyses, two rod-shaped macroplacoids and a small triangular microplacoid (Fig. 15A, D-E). The macroplacoid length sequence is $2<1$. The first macroplacoid exhibits central constriction whereas the second macroplacoid is sub-terminally constricted (Figs 15D-E, 17C).

Eggs (measurements and statistics in Table 5)

Laid freely, whitish, spherical or ovoid (Figs 18A-B, 19A). The surface between processes is smooth, with thickenings/striae often radiating from the processes bases (Figs 18B-D, 19B-C, E-F). Under PCM, these thickenings together with labyrinthine layer within chorion are visible as dark dots and lines on the surface between processes, whereas under SEM they are smooth striae coming out of the process bases (Figs 18B-D and 19B-C, E-F, respectively). Under SEM, the surface between processes and between the peribasal striae is covered with micropores (Fig. 19E-F). Processes are of conical shape, with elongated apices which are sometimes bi- or trifurcated (Figs 18E-H, 19A-D). The labyrinthine layer between the process walls is clearly visible under LCM as a reticular pattern
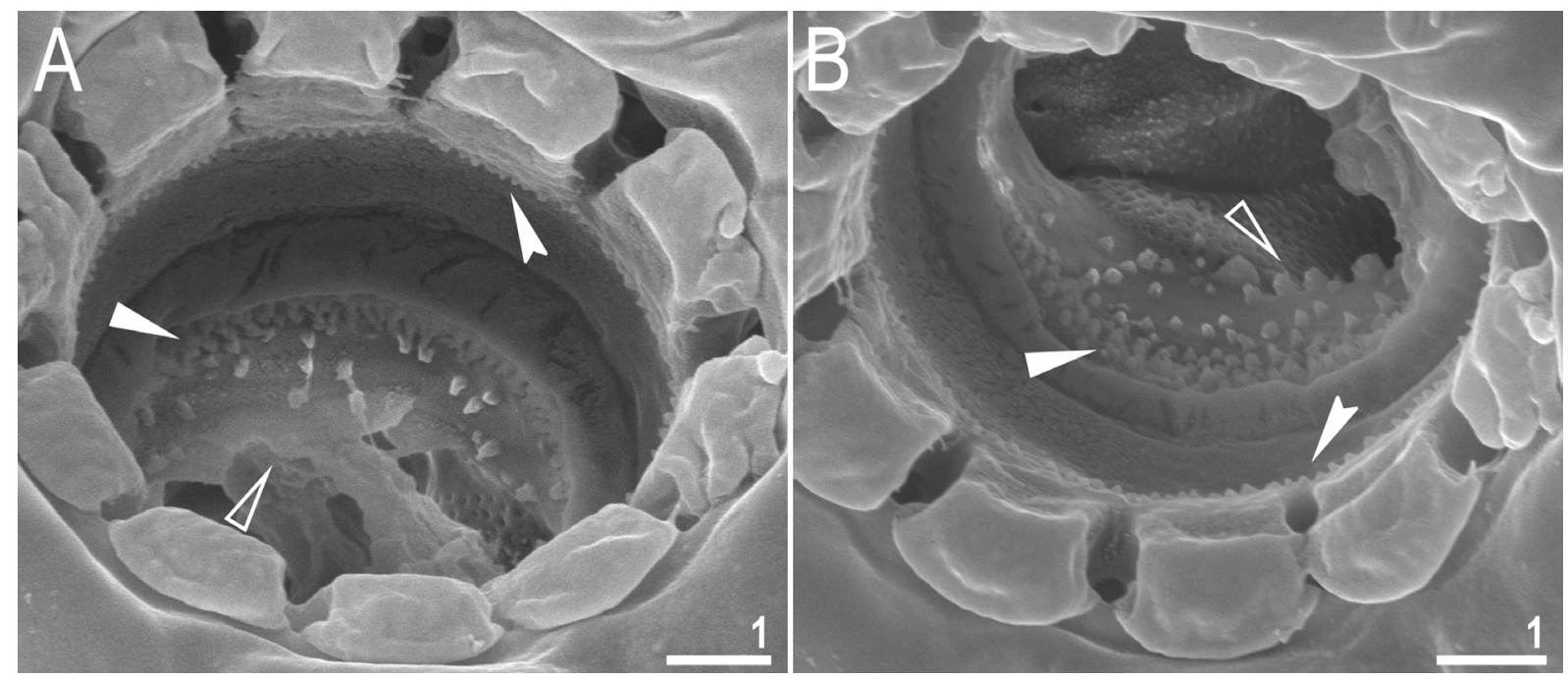

Fig. 16. Tenuibiotus zandrae sp. nov. The oral cavity armature seen in SEM (paratype). The oral cavity armature of a single paratype seen in SEM from different angles, dorsal (A) and ventral (B) view, respectively. Filled indented arrowheads indicate the first band of teeth in the oral cavity, filled flat arrowheads indicate the second band of teeth in the oral cavity, whereas empty flat arrowheads indicate the third band of teeth in the oral cavity. Scale bars in $\mu \mathrm{m}$. 

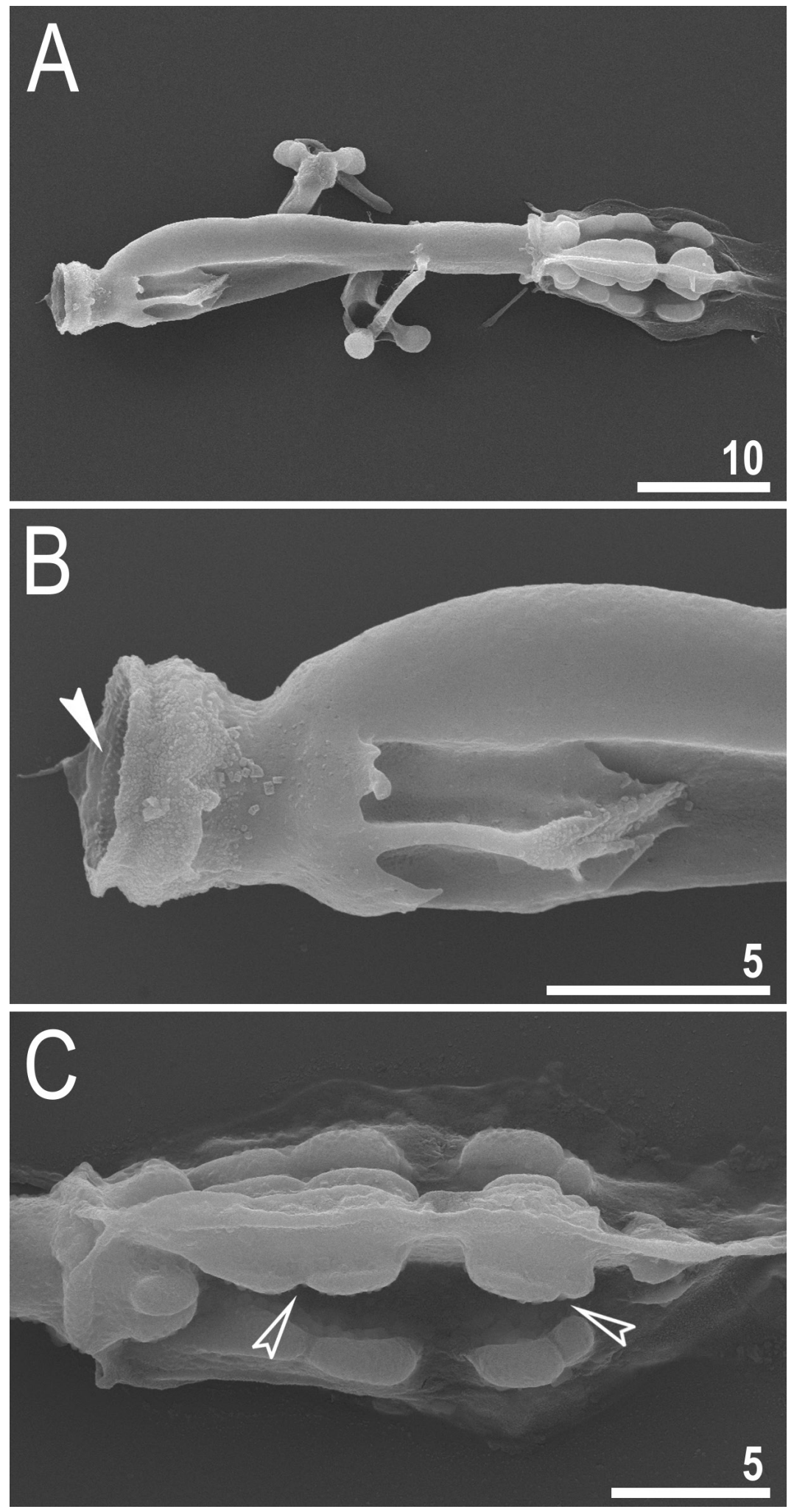

Fig. 17. Tenuibiotus zandrae sp. nov. Buccal apparatus seen in SEM (paratype). A. Entire buccal apparatus. B. Lateral view of the buccal crown. C. Placoids. Filled indented arrowhead indicate the first band of teeth in the oral cavity, empty indented arrowheads indicate the central constriction in the first macroplacoids and the subterminal constriction in the second macroplacoid. Scale bars in $\mu \mathrm{m}$. 
STEC D. et al., Two new Macrobiotidae species from Greenland

with sinuous margins (Fig. 18C-D). The elongated meshes decrease in size from the base to the top of the processes (Fig. 18C-D). Under SEM, the surface of the processes is covered with small tubercles, whereas the surface of the elongated apices is smooth (Fig. 18B-E).
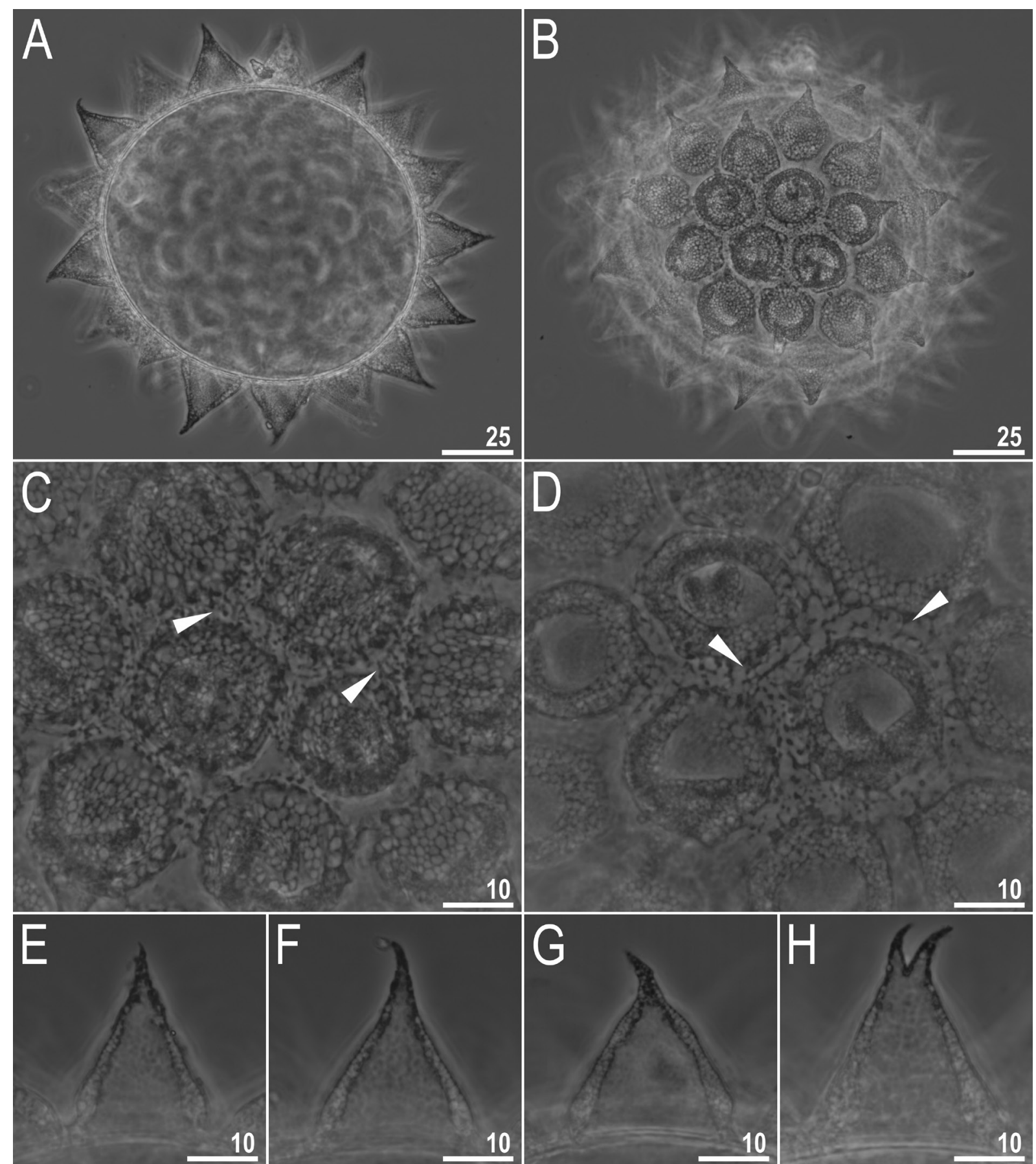

Fig. 18. Tenuibiotus zandrae sp. nov. Egg chorion morphology seen in PCM. A. Midsection under $400 \times$ magnification. B. Surface under $400 \times$ magnification. C-D. Surface between processes under $1000 \times$ magnification. $\mathbf{E}-\mathbf{H}$. Midsections of processes of four different eggs under $1000 \times$ magnification. Filled flat arrowheads indicate thickenings/striae which are visible as dark dots and lines on the surface between processes. Scale bars in $\mu \mathrm{m}$. 


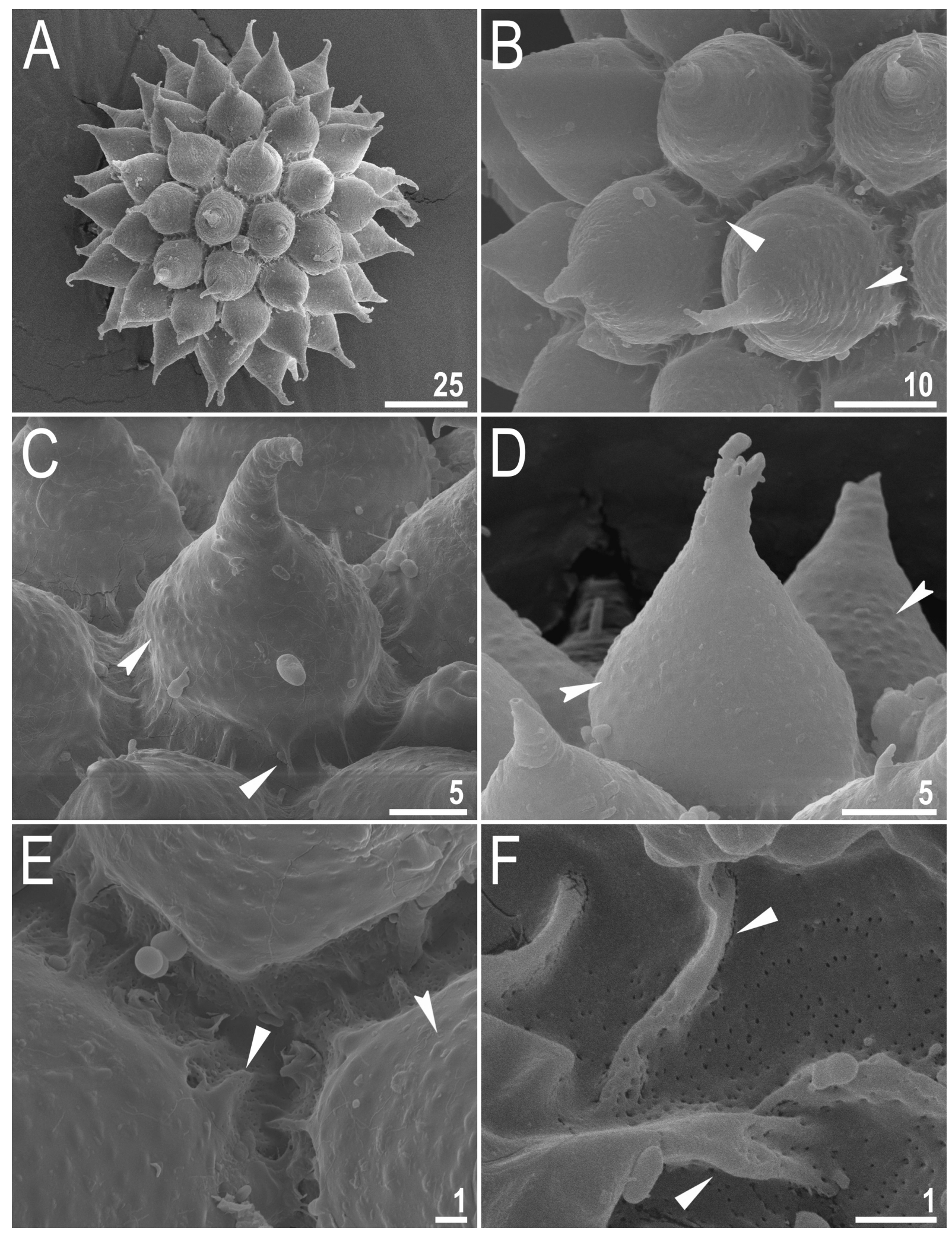

Fig. 19. Tenuibiotus zandrae sp. nov. Egg chorion morphology seen in SEM. A. Entire egg. B. Magnification of the egg surface. C-F. Details of the egg processes and surface between them. Filled flat arrowheads indicate thickenings/striae on the surface between processes and filled indented arrowheads indicate small tubercles on the process walls. Scale bars in $\mu \mathrm{m}$. 
STEC D. et al., Two new Macrobiotidae species from Greenland

Table 5. Measurements (in $\mu \mathrm{m}$ ) of selected morphological structures of the eggs of Tenuibiotus zandrae sp. nov. mounted in Hoyer's medium (N: number of eggs/structures measured; RANGE refers to the smallest and the largest structure among all measured specimens; SD: standard deviation).

\begin{tabular}{lcccc}
\hline CHARACTER & N & RANGE & MEAN & SD \\
\hline Egg bare diameter & 30 & $90,9-125,0$ & 108,3 & 8,5 \\
Egg full diameter & 30 & $136,0-182,3$ & 161,8 & 11,4 \\
Process height & 90 & $16,8-38,9$ & 28,3 & 3,9 \\
Process base width & 90 & $13,6-29,6$ & 21,3 & 2,7 \\
Process base/height ratio & 90 & $47-96 \%$ & $76 \%$ & $9 \%$ \\
Inter-process distance & 90 & $1,3-4,6$ & 2,6 & 0,7 \\
Number of processes on the egg circumference & 30 & $13-15$ & 14,2 & 0,7 \\
\hline
\end{tabular}

\section{Reproduction}

The examination of specimens freshly mounted in Hoyer's medium did not revealed any spermathecae or testes filled with spermatozoa. Also, male secondary sexual dimorphism traits such as lateral gibbosities on legs IV were absent. Thus, reproductive mode could not be unambiguously determined.

\section{DNA sequences}

We obtained sequences of good quality for all four of the above-mentioned DNA markers. Sequences of each marker were represented by single haplotypes:

18S rRNA sequence (GenBank: MN443040), 1035 bp long;

28S rRNA sequence (GenBank: MN443035), 780 bp long;

ITS-2 sequence (GenBank: MN443038), 439 bp long;

COI sequence (GenBank: MN444827), 658 bp long.

\section{Morphological observations of comparative material}

\section{Amended description of Tenuibiotus voronkovi}

The examination of the holotype and paratype of $T$. voronkovi under LCM revealed the presence of granulation on the body cuticle. Faint granulation with small and uniformly sized granules is regularly arranged and covers the dorso-medial region of the body, from its cephalic to the caudal end (Fig. 20A). On the dorso-lateral surface of the body, granulation is unevenly distributed and resembles patches of granules, within which granule size gradually increases in the dorsal to lateral direction (Fig. 20B). The granulation is absent or not visible in LCM on the ventral side of the body. Similarly, the granulation is absent on the legs except a typical dense granulation patch on the external and internal surface of the legs near the claws. However, note that this observation was made on two different specimens (not very well oriented/positioned and stretched on the slide) thus, the certain distribution pattern of body granulation requires a further examination when a new population of $T$. voronkovi becomes available. As in the original description, the eggs of $T$. voronkovi have small conical processes with elongated and flexible apices which are often folded and not clearly visible or even broken. (Figs 21A, C-J, 22). The process walls are smooth, without any obvious thickenings or tubercles (Fig. 22) but with obvious annulation and with the labyrinthine layer within process walls, visible under LCM as roundish polygonal reticulation (Fig. 21C, E-F), on one egg being abnormally developed and visible more like pores than true reticulation (Fig. 21D). Under SEM, the surface between processes is covered with short irregular striae/ridges/wrinkles which often radiate from the process bases, with small micropores randomly scattered in between them (Fig. 22). However, under PCM the surface is visible as being 
covered with dark dots which are probably the thickenings of the labyrinthine layer within the chorion (Fig. 21B).

The morphological analysis conducted on two populations designated as " $T$. voronkovi" by Zawierucha et al. (2016a), from Edgeøya and Nordaustlandet (islands within the Svalbard archipelago, Norway), showed distinct differences in cuticle morphology in comparison to the $T$. voronkovi type series. Specifically, animals of the Edgeøya population exhibit faint, dense and uniformly distributed granulation on the whole dorso-lateral cuticle from its cephalic to the caudal end (excluding ventral and leg cuticle) (Fig. 23A), whereas this granulation is absent or not visible under LCM in animals of the Nordaustlandet population. The morphology of egg processes in both these populations is very similar: specifically, processes are of a conical shape with elongated apices, with the labyrinthine layer between the process walls clearly visible under LCM as a reticular pattern with sinuous margins and elongated meshes decreasing in size from the base to the processes top in most cases (Figs 23B-D, 24). Other traits are as described by Zawierucha et. al. (2016a) however, it should be noted that as for the similarly to $T$. voronkovi, no more conclusions can be made based on this material due to the bad condition of the slides, with bubbles of air and crystalized Hoyer which prevent further investigation and limit the number of specimens suitable for imaging.

\section{Discussion}

\section{Phenotypic differential diagnosis of Macrobiotus engbergi sp. nov.}

Macrobiotus engbergi sp. nov., by having the patagonicus type of oral cavity armature (i.e., with only the $2^{\text {nd }}$ and $3^{\text {rd }}$ bands of teeth in the oral cavity visible under LCM), the persimilis type of egg shell ornamentation (i.e., with a continuous smooth chorion, never with pores or reticulum) and large lenticular pores within the body cuticle is most similar to a species recently discovered in Ecuador, Macrobiotus dulciporus Roszkowska et al., 2019, but differs from it by: the presence of 1-2 rows of small teeth in the first band of teeth within the oral cavity armature (4-5 rows of small teeth in the first band in M. dulciporus; this character is visible only in SEM), a clearly visible serration or indentation of the terminal discs of the egg processes under LCM (terminal discs smooth under LCM in M. dulciporus), the presence of microgranulation on the margins of the terminal discs of the egg
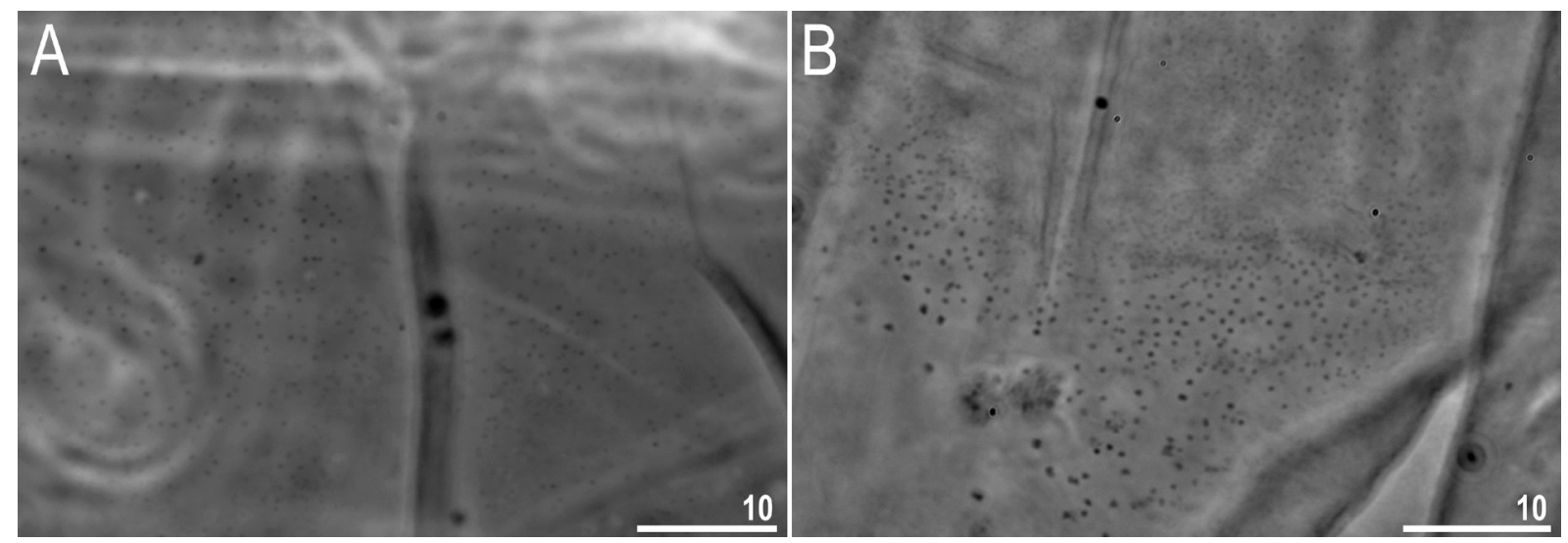

Fig. 20. Tenuibiotus voronkovi (Tumanov, 2007). Body granulation seen in PCM. A. Uniformly distributed granulation of uniform size on the dorso-medial part of the body (cephalic region, paratype). B. Patch of dorso-lateral granulation composed of granules of different size (holotype). Scale bars in $\mu \mathrm{m}$. 
processes (microgranulation absent in M. dulciporus; this character is visible only in SEM), the presence of a smooth chorion surface between the processes under SEM (the surface under SEM slightly wrinkled with 1-2 obvious rows of peribasal thickenings/tubercles in $M$. dulciporus). Remarks: The new species has a secondary sexual dimorphic trait in the form of gibbosities on legs IV in males, and this trait has not been seen in the population of $M$. dulciporus, since males were not observed. Thus, this character cannot be used for differentiation until the reproduction mode of $M$. dulciporus is ascertained.

\section{Genotypic differential diagnosis of Macrobiotus engbergi sp. nov.}

The ranges of uncorrected genetic p-distances between the new species and species of the Macrobiotus hufelandi complex, for which sequences are available from GenBank, are as follows (from the most to the least conservative):
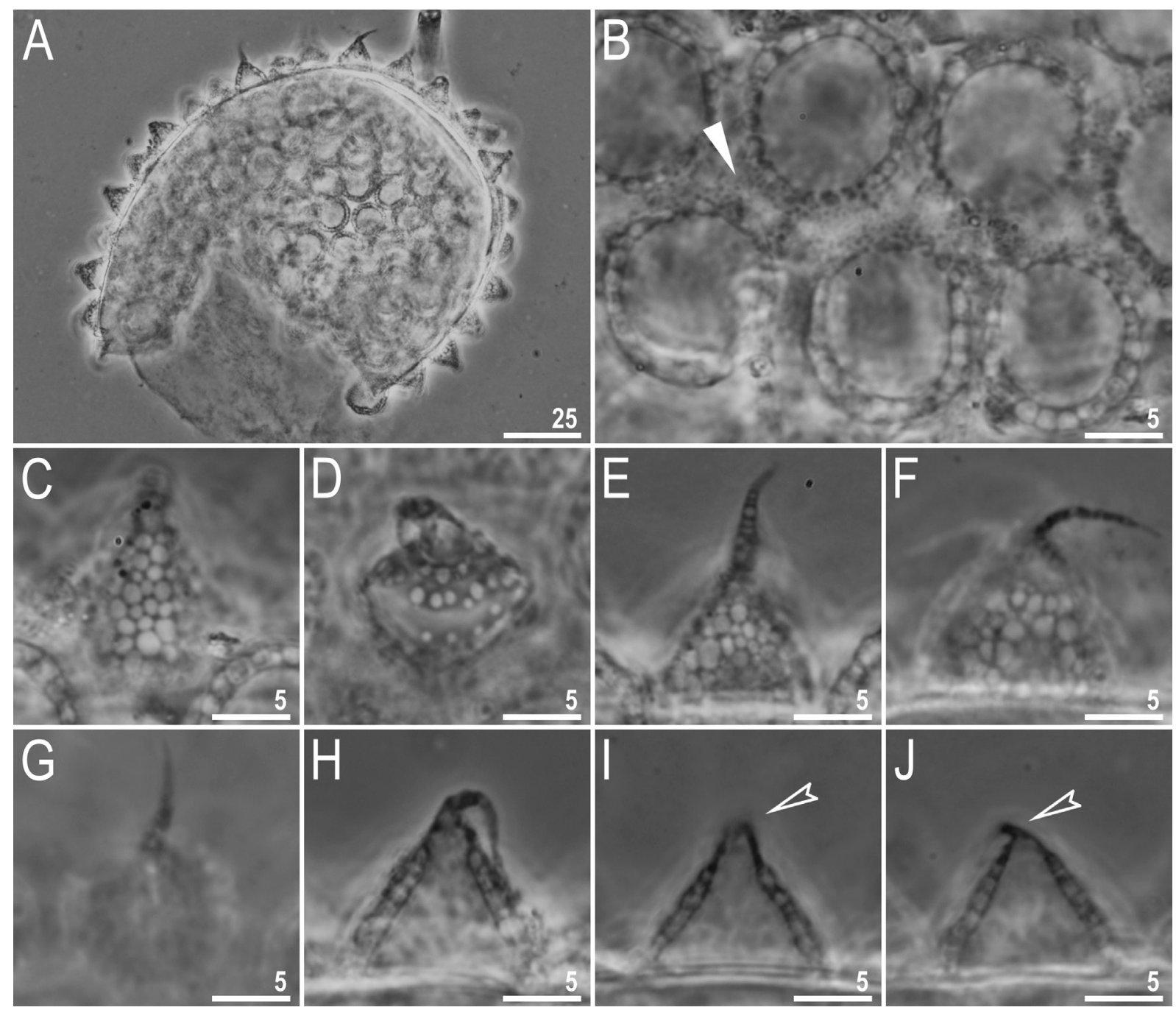

Fig. 21. Tenuibiotus voronkovi (Tumanov, 2007) Egg chorion morphology seen in PCM. A. Midsection under $400 \times$ magnification. B. Surface between processes under $1000 \times$ magnification. C-J. Details of egg processes under $1000 \times$ magnification. Filled flat arrowhead indicates thickenings/striae/sculpture which are visible as dark dots on the surface between processes and indented empty arrowheads indicate broken apices of the egg processes. Scale bars in $\mu \mathrm{m}$. 
18S rRNA: $0.7-4.2 \%$ (2.6\% on average), with the most similar being M. caelestis Coughlan et al., 2019 from Kyrgyzstan (MK737073) and the least similar being M. polypiformis Roszkowska et al., 2017 from Ecuador (KX810008);

28S rRNA: $3.8-13.2 \%$ (8.2\% on average), with the most similar being $M$. caelestis from Kyrgyzstan (MK737071) and the least similar being M. polypiformis from Ecuador (KX810009);

COI: $18.3-23.9 \%$ (20.8\% on average), with the most similar being $M$. terminalis Bertolani \& Rebecchi, 1993 from Italy (AY598775) and the least similar being M. kamilae Coughlan \& Stec, 2019 from India (MK737920-1);

ITS-2: $10.6-32.7 \%$ (24.6\% on average), with the most similar being M. polonicus Pilato et al., 2003 from Poland (HM150647) and the least similar M. polypiformis from Ecuador (KX810010).
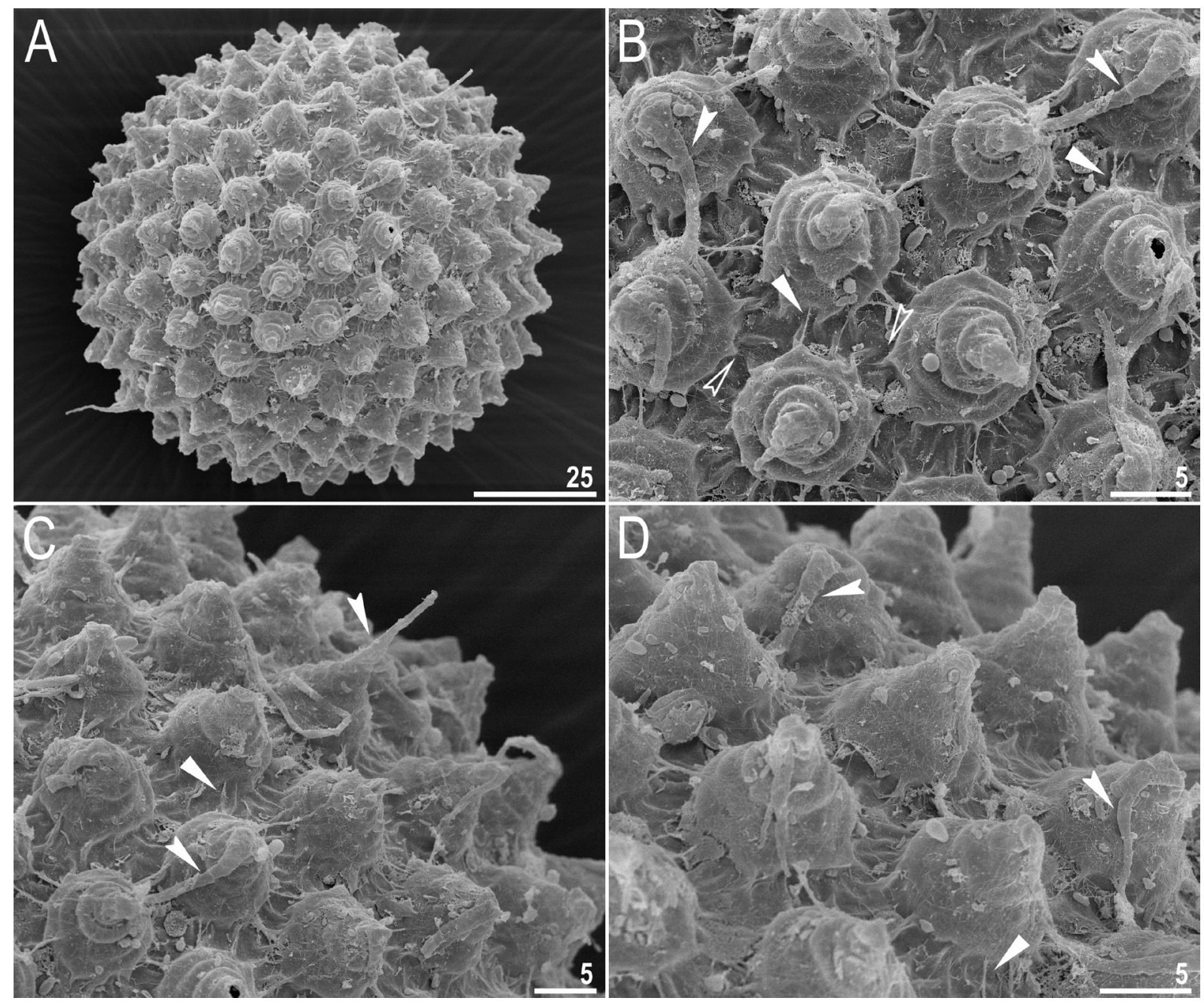

Fig. 22. Tenuibiotus voronkovi (Tumanov, 2007), egg chorion morphology seen in SEM. A. Entire egg. B-D. Details of the egg processes and surface between them. Filled flat arrowheads indicate thickenings/ striae on the surface between processes, filled indented arrowheads indicate elongated and flexible apices of egg processes which are often folded, whereas empty indented arrowheads indicate micro pores on the chorion surface between processes. Scale bars in $\mu \mathrm{m}$. 
STEC D. et al., Two new Macrobiotidae species from Greenland

\section{Phenotypic differential diagnosis of Tenuibiotus zandrae sp. nov.}

Tenuibiotus zandrae sp. nov., by having two macroplacoids as well as elongated and sharp apices of the egg processes, is most similar to seven Tenuibiotus species, T. bondavallii (Manicardi, 1989), T. ciprianoi (Guil et al., 2007), T. danilovi (Tumanov, 2007), T. hyperonyx (Maucci, 1983), T. kozharai (Biserov, 1999), T. mongolicus (Maucci, 1988) and T. voronkovi (Tumanov, 2007), but it differs specifically from:

Tenuibiotus bondavallii, known only from a few Arctic and Sub-arctic localities in Canada (including type locality) and Russia (Manicardi 1989; Biserov 1996; Dudichev \& Biserov 2000; Sutcliffe \& Blake 2000; Kaczmarek et al. 2016), by the absence of small areoles on the chorion surface between the processes (one row of small areoles surrounding the egg processes present in T. bondavallii);

Tenuibiotus ciprianoi, known only from its type locality in Spain (Guil et al. 2007), by: the presence of dense granulation patches on the internal surface on legs I-III (internal leg surface smooth in $T$. ciprianoi), the processes distant from each other enabling the observation of the chorion surface covered
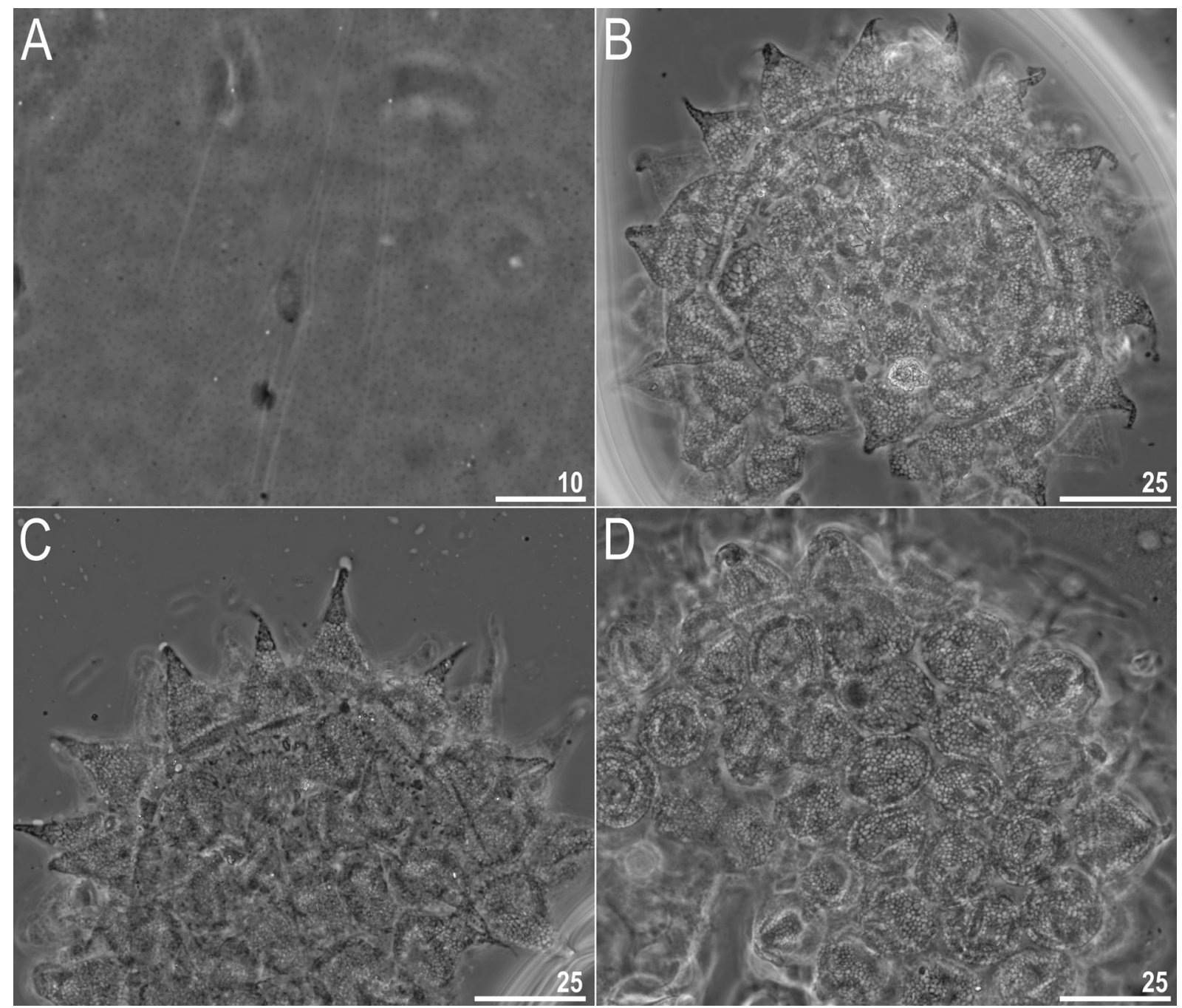

Fig. 23. Tenuibiotus cf. voronkovi (Tumanov, 2007) from the Edgeøya population, body cuticle and eggs seen in PCM. A. Uniformly distributed granulation on the dorsal side of the body at the level between leg pairs II and III. B-D. Three different eggs under 1000× magnification. Scale bars in $\mu \mathrm{m}$. 
with thickenings between processes, visible under LCM as dots and lines (chorion surface between processes invisible under LCM due to small distance between neighbouring processes, which are almost always in contact to each other in T. ciprianoi), the absence of a bubble-like structure/reticulation system in the elongated apices of the egg processes (the bubble like structure/reticulation system present in T. ciprianoi), and by wider egg process bases (13.6-29.6 $\mu \mathrm{m}$ in the new species vs $6.9-9.9 \mu \mathrm{m}$ in T. ciprianoi);

Tenuibiotus danilovi, known only from its type locality in Kyrgyzstan (Tumanov 2007), by: the presence of eyes (eyes absent in $T$. danilovi), the presence of continuous granulation on the body cuticle (only small patchy areas of granulation present, only on the ventral body cuticle, in $T$. danilovi), the presence of a second band of teeth in the oral cavity visible in LCM (the second band of teeth absent or not visible under LCM in T. danilovi), the presence of three separate teeth in the dorsal portion of the third band of teeth in the oral cavity (the dorsal portion of the third band fused into one arc with two evident granules/ teeth in T. danilovi), the presence of teeth in the ventral portion of the third band of teeth visible under LCM (the ventral portion of the oral cavity armature absent or invisible under LCM in T. danilovi), slightly more anterior stylet support insertion point $(p t=71.2-73.3$ in the new species vs 76.9-77.3 in

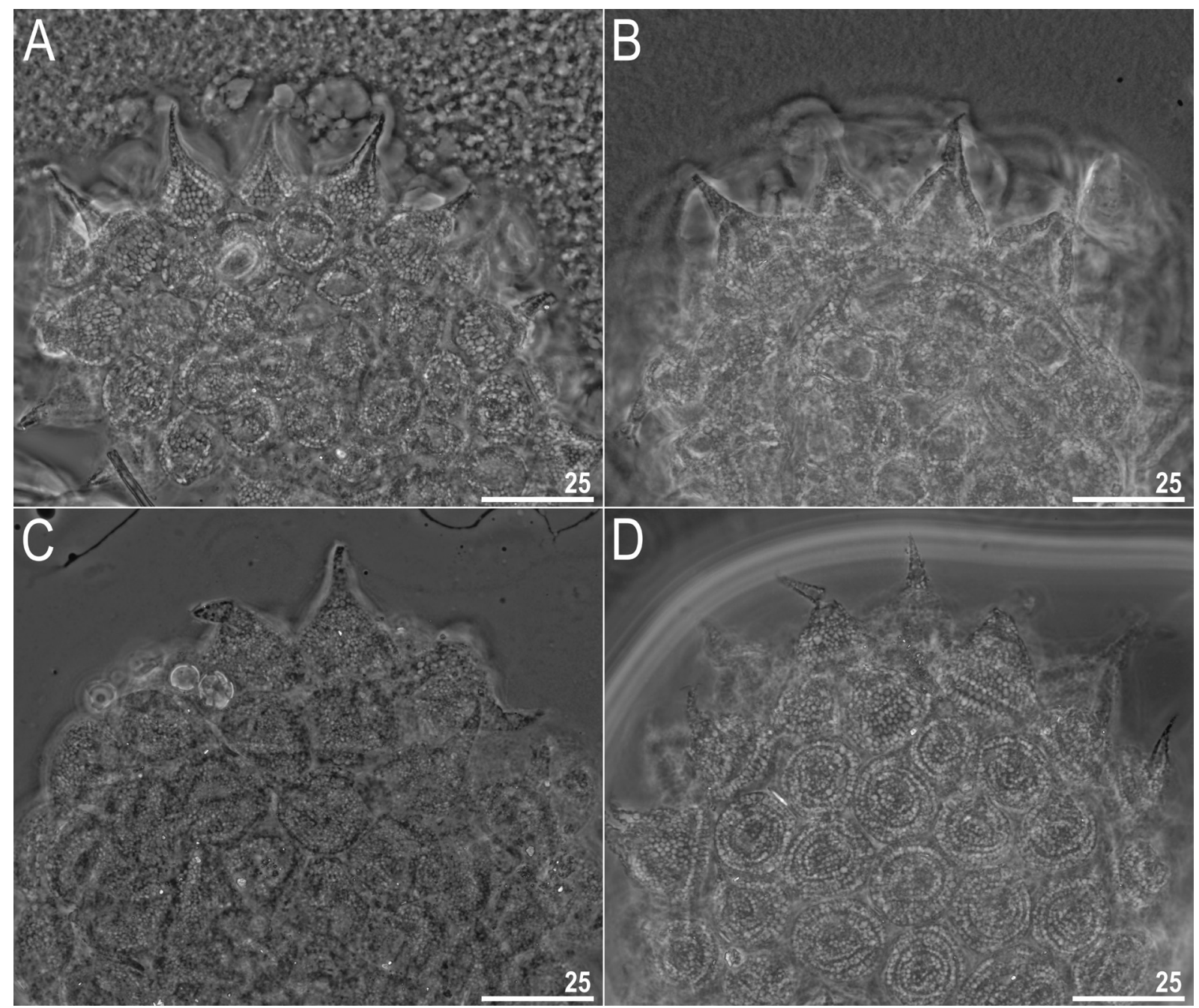

Fig. 24. Tenuibiotus $c f$. voronkovi (Tumanov, 2007) from the Nordaustlandet population, eggs seen in PCM. Four different eggs under $1000 \times$ magnification. Scale bars in $\mu \mathrm{m}$. 
STEC D. et al., Two new Macrobiotidae species from Greenland

T. danilovi), higher egg processes (16.8-38.9 $\mu \mathrm{m}$ in the new species vs $12.0-13.5 \mu \mathrm{m}$ in $T$. danilovi) and by wider egg process bases (13.6-29.6 $\mu \mathrm{m}$ in the new species vs $8.0-8.5 \mu \mathrm{m}$ in $T$. danilovi);

Tenuibiotus hyperonyx, known only from its type locality in Italy (Maucci 1983), by: the absence of pores in the body cuticle (the pores are present in T. hyperonyx), the presence of a microplacoid in the pharynx (the microplacoid absent in T. hyperonyx), the presence of reticulation on the egg processes caused by the labyrinthine layer (the reticulation absent in T. hyperonyx), higher egg processes $(16.8-38.9 \mu \mathrm{m}$ in the new species vs 10.0-11.0 $\mu \mathrm{m}$ in T. hyperonyx) and by wider egg process bases $(13.6-29.6 \mu \mathrm{m}$ in the new species vs 5.0-6.0 $\mu \mathrm{m}$ in T. hyperonyx);

Tenuibiotus kozharai, known only from its type locality in Turkmenistan (Biserov 1999), by: the presence of well-developed and distinct accessory points on the primary branches of all claws (the accessory points weakly developed, short and connected with primary branches over almost their entire length in T. kozharai), higher egg processes (16.8-38.9 $\mu \mathrm{m}$ in the new species vs $5.0-9.0 \mu \mathrm{m}$ in T. kozharai), and by wider egg process bases (13.6-29.6 $\mu \mathrm{m}$ in the new species vs $6.0-6.5 \mu \mathrm{m}$ in T. kozharai);

T. mongolicus, known only from its type locality in Mongolia (Maucci 1988), by: the presence of eyes (eyes absent in T. mongolicus), the presence of continuous granulation on the body cuticle (granulation on body cuticle absent in T. mongolicus; note: similarly to the new species, specimens of T. mongolicus were also observed under SEM by Maucci (1988)), different morphology of claws (not very elongated primary branches of all claws which after furcation with secondary branches at a right angle from the common tract extend immediately horizontally in the opposite direction as the secondary branch in the new species vs. primary braches clearly elongated which after furcation with secondary branches at a right angle from the common tract extend immediately almost vertically in $T$. mongolicus), the presence of faintly marked tubercles on the surface of the egg processes (the surface of process walls smooth, without tubercles in T. mongolicus; this character is visible only in SEM) and slightly higher egg processes (16.8-38.9 $\mu \mathrm{m}$ (average $28.3 \pm 3.9 \mu \mathrm{m}$ ) in the new species vs 15.0-17.0 $\mu \mathrm{m}$ in T. mongolicus);

Tenuibiotus voronkovi, known only from its type locality in Spitsbergen (Norway) (Tumanov 2007, please see also notes on this species below), by: the presence of granulation uniform in size on the entire body cuticle (the granulation present only in dorsal and dorso-lateral regions, in the latter being composed of variable-sized granules in $T$. voronkovi), the presence of inflexible, stout, not very elongated apices of the egg processes (the apices are very flexible, narrow and more elongated in $T$. voronkovi), the presence of reticulation caused by the labyrinthine layer within process walls with elongated meshes decreasing in size from the base to the process top (roundish polygonal reticulation with uniform size of meshes present in $T$. voronkovi), the presence of faintly marked tubercles on the process wall surface and egg processes without annulation (the surface of process walls smooth, without tubercles, but with obvious annulations in T. voronkovi; this character is visible only in SEM), by a denser distribution of micropores between the striae/ridges on the chorion surface between processes (micropores with lower density scattered randomly on the chorion surface between processes in $T$. voronkovi; this character is visible only in SEM), higher processes (16.8-38.9 $\mu \mathrm{m}$ in the new species vs. 9.6-14.8 $\mu \mathrm{m}$ in $T$. voronkovi) and a lower number of processes on the egg circumference (13-15 in the new species vs. 20-22 in T. voronkovi). Remarks: for this comparison, we only used the original description of T. voronkovi, type specimens and a newly found egg from the original sample, as the designation of two additional populations in the redescription by Zawierucha et al. (2016a) as "T. voronkovi" is uncertain. See also specific notes below.

\section{Genotypic differential diagnosis of Tenuibiotus zandrae sp. nov.}

To date, DNA sequences of only one Tenuibiotus species, namely of a population identified by Zawierucha et al. (2016a) as "T. voronkovi", have been published and we used all of them in this comparison: 
18S rRNA: no differences in the analysed fragment between the new species and T. voronkovi (KX810045); 28 S rRNA: $0.3 \%$ and $0.4 \%$ between the new species and two haplotypes of $T$. voronkovi (KX81004950 , respectively);

ITS-2: $2.4 \%$ between the new species and all three haplotypes of T. voronkovi (KX810046-48); COI: $14.4 \%, 15.3 \%$ and $13.7 \%$ between the new species and all three haplotypes of $T$. voronkovi (KX810042-44, respectively).

\section{Notes on Tenuibiotus voronkovi (Tumanov, 2007)}

Tenuibiotus voronkovi was described from Ny Ålesund (Konigsfjorden, Spitsbergen, Norway) based on two animals and five eggs. Since the animals from the original description have destroyed claws on the hind legs and there was a lack of complete morphometric data for the buccal tube and claws, Zawierucha et al. (2016a) aimed to redescribe this species. They supplemented the original description with a reexamination of the paratype and one egg from the type series alongside with additional animals and eggs from three new populations from Spitsbergen, Nordaustlandet and Edgeøya (all within Svalbard Archipelago, Norway). Together with a morphological redescription, they also provided DNA sequences of four molecular markers (18S rRNA, 28S rRNA, ITS-2 and COI) which were obtained from specimens of the Nordaustlandet population. In this study, we once again re-examined the type series of $T$. voronkovi together with one additional egg (SEM observation) from the original sample in which this species was discovered (Tumanov 2007). We also examined the slides with animals and eggs of the Nordaustlandet and the Edgeøya populations studied by Zawierucha et al. (2016a). Although the holotype and the paratype are partially destroyed and not optimally oriented on the slides, and even though the slides with specimens from Nordaustlandet and Edgeøya are in bad condition, we were able to note some important morphological differences between the type series and the other two populations. Specifically, the holotype and the paratype of $T$. voronkovi exhibit fine granulation on the dorso-medial and dorso-lateral cuticle that seems to be unevenly distributed from the cephalic to the caudal end of the body (Fig. 20AB). Fine granulation is also present on the dorsal and dorso-lateral body cuticle in specimens from Edgeøya, but here its distribution and size are uniform (Fig. 23A). However, granulation on the body cuticle is absent or invisible in specimens of the Nordaustlandet population. The examination of eggs of T. voronkovi showed that the processes exhibit very narrow, elongated and flexible apices (Figs 21A-J, 22A-D), which is in contrast to the eggs from Nordaustlandet and Edgeøya, which are more similar to the eggs of T. zandrae sp. nov. described herein (Figs 18A-H, 19A-F, 23B-D, 24A-D). Nevertheless, the processes presented in figures 17 and 18 in Zawierucha et al. (2016a) are more similar to those of T. voronkovi, with strongly elongated and flexible apices. Moreover, the SEM images of the Tenuibiotus eggs presented by Zawierucha et al. (2013), who examined both populations from Nordaustlandet and Edgeøya, are indeed very similar to those of T. voronkovi in process proportions as well as by having annulation on the processes. These new findings question the designation of additional populations by Zawierucha et al. (2016a) as T. voronkovi. All these observations suggest that the most parsimonious scenario is that the additional material used within the mentioned redescription comprises three separate species: T. voronkovi mixed with T. zandrae sp. nov. (the Edgeøya population), and a new Tenuibiotus species (the Nordaustlandet population). However, since the condition of slides and specimens is bad and only one population (Nordaustlandet) has been genetically characterised, it cannot be excluded that even more species are present there. Thus, also the designation of DNA sequences presented by Zawierucha et al. (2016a) as sequences of $T$. voronkovi should be treated as invalid. The comparison of these sequences with sequences of $T$. zandrae sp. nov. revealed a close relationship between these species by a high similarity of the three nuclear markers typically used in tardigrade taxonomy. This pattern has already been noted in some tardigrade species within the genera Richtersius Pilato \& Binda, 1989, Paramacrobiotus Guidetti et al., 2009 and Mesobiotus Vecchi et al., 2016 (Guidetti et al. 2016, 2019; Stec 2019; Stec et al. 2020). Given that specimens of the Nordaustlandet population are morphologically more similar to $T$. zandrae sp. nov. than to specimens from the type series of $T$. voronkovi, it is even more probable that they represent a new distinct species. To summarise, $T$. voronkovi still urgently 
STEC D. et al., Two new Macrobiotidae species from Greenland

needs a detailed redescription based on a new population collected exactly from the locus typicus in $\mathrm{Ny}$ Ålesund. Therefore, until new detailed morphological and genetic data for this species are available, the two populations (Nordaustlandet and Edgeøya, respectively) studied by Zawierucha et al. (2016a) and the associated DNA sequences (KX810042-50) should be referred as $T$. cf. voronkovi.

\section{Conclusions}

Thanks to detailed morphological and morphometric analysis as well as integration of these data with DNA sequences of the studied tardigrade populations, we described two tardigrade species of the family Macrobiotidae new for science. Moreover, the re-examination of the type series of T. voronkovi, but also slides with specimens of two Tenuibiotus populations studied by Zawierucha et al. (2016a), enabled us to amend the description of this species. At the same time, our results question the designation of these two populations and the DNA sequences presented in the redescription as representing T. voronkovi.

\section{Acknowledgments}

We are very grateful to Karen Bjerregaard, Kjeld Akaaraq Emil Mølgaard and Lars Engberg Hansen who collected the samples in Greenland, in which we have discovered the two new species. The samples comprising new species were collected during the project: The Secret of the Greenlandic Springs, Carlsberg Foundation (grant no. 2012_01_0123 to R.M.K.). We would also like to thank to Krzysztof Zawierucha and Łukasz Kaczmarek, who kindly send us microscope slides with animals and eggs of the Nordaustlandet and Edgeøya populations, which were used in the recent redescription of T. voronkovi. We are also grateful to Piotr Gąsiorek for the buccal-apparatus extraction. Lukasz Michalczyk and two anonymous reviewers are also acknowledged for their suggestions and corrections which greatly improved our work. The SEM study of the Tenuibiotus voronkovi egg was carried out with the use of equipment of the Core Facilities Center "Centre for Molecular and Cell Technologies" of St. Petersburg State University. The study was supported by the Preludium programme of the Polish National Science Centre (grant no. 2018/31/N/NZ8/03096 to DS) and partially supported by a grant from the European Commission's programme "Transnational Access to Major Research Infrastructures" to SYNTHESYS (grant no. DK-TAF-2693) to DS. Some of the analyses were carried out with the equipment purchased from the Sonata Bis programme of the Polish National Science Centre (grant no. 2016/22/E/NZ8/00417 to Łukasz Michalczyk).

\section{References}

Bertolani R. \& Rebecchi L. 1993. A revision of the Macrobiotus hufelandi group (Tardigrada, Macrobiotidae), with some observations on the taxonomic characters of eutardigrades. Zoologica Scripta 22: 127-152. https://doi.org/10.1111/j.1463-6409.1993.tb00347.x

Bertolani R., Rebecchi L., Giovannini I. \& Cesari M. 2011a. DNA barcoding and integrative taxonomy of Macrobiotus hufelandi C.A.S. Schultze 1834, the first tardigrade species to be described, and some related species. Zootaxa 2997: 19-36. https://doi.org/10.11646/zootaxa.2997.1.2

Bertolani R., Biserov V., Rebecchi L. \& Cesari M. 2011b. Taxonomy and biogeography of tardigrades using an integrated approach: new results on species of the Macrobiotus hufelandi group. Invertebrate Zoology 8 (1): 23-36. https://doi.org/10.15298/invertzool.08.1.05

Bertolani R., Guidetti R., Marchioro T., Altiero T., Rebecchi L. \& Cesari M. 2014. Phylogeny of Eutardigrada: New molecular data and their morphological support lead to the identification of new evolutionary lineages. Molecular Phylogenetics and Evolution 76: 110-126.

https://doi.org/10.1016/j.ympev.2014.03.006

Biserov V.I. 1996. Tardigrada of the Novaya Zemlya Archipelago, collected by the Marine Arctic Complex Expedition in 1994. Arthropoda Selecta 5: 151-157. 
Biserov V.I. 1999. Tardigrada of Turkmenistan, with description of three new species. Zoologischer Anzeiger 238: 157-167.

Casquet J.T., Thebaud C. \& Gillespie R.G. 2012. Chelex without boiling, a rapid and easy technique to obtain stable amplifiable DNA from small amounts of ethanol-stored spiders. Molecular Ecology Resources 12: 136-141. https://doi.org/10.1111/j.1755-0998.2011.03073.x

Cesari M., Bertolani R., Rebecchi L. \& Guidetti R. 2009. DNA barcoding in Tardigrada: the first case study on Macrobiotus macrocalix Bertolani \& Rebecchi 1993 (Eutardigrada, Macrobiotidae). Molecular Ecology Resources 9 (3): 699-706. https://doi.org/10.1111/j.1755-0998.2009.02538.x

Cesari M., Giovanni I., Bertolani R. \& Rebecchi L. 2011. An example of problems associated with DNA barcoding in tardigrades: a novel method for obtaining voucher specimens. Zootaxa 3104: 42-51.

Coughlan K., Michalczyk Ł. \& Stec D. 2019. Macrobiotus caelestis sp. nov., a new tardigrade species (Macrobiotidae: hufelandi group) from the Tien Shan Mountains (Kyrgyzstan). Annales Zoologici 69 (3): 499-513. https://doi.org/10.3161/00034541ANZ2019.69.3.002

Coughlan K. \& Stec D. 2019. Two new species of the Macrobiotus hufelandi complex (Tardigrada: Eutardigrada: Macrobiotidae) from Australia and India, with notes on their phylogenetic position. European Journal of Taxonomy 573: 1-38. https://doi.org/10.5852/ejt.2019.573

Dastych H. 1980. Niesporczaki (Tardigrada) Tatrzańskiego Parku Narodowego. Monografie Fauny Polski 9: 1-232.

Degma P. \& Guidetti R. 2007. Notes to the current checklist of Tardigrada. Zootaxa 1579: 41-53. https://doi.org/10.11646/zootaxa.1579.1.2

Degma P. \& Guidetti R. 2018. Tardigrade taxa. In: Schill, R.O. (ed.) Water Bears: The Biology of Tardigrades: 371-409, Springer, Stuttgart. https://doi.org/10.1007/978-3-319-95702-9_15

Degma P., Bertolani R. \& Guidetti R. 2009-2019. Actual checklist of Tardigrada species. Online. Università degli Studi di Modena e Reggio Emilia. https://doi.org/10.25431/11380_1178608

Dudichev A.L. \& Biserov V.I. 2000. Tardigrada from Iturup and Paramushir Islands (The Kuril Islands). Zoologicheskii Zhurnal 79: 771-778.

Eibye-Jacobson J. 2001. ANew Method for Making SEM Preparations of the Tardigrade Buccopharyngeal Apparatus. Zoologischer Anzeiger 240: 309-319. https://doi.org/10.1078/0044-5231-00038

Folmer O., Black M., Hoeh W., Lutz R. \& Vrijenhoek R. 1994. DNA primers for amplification of mitochondrial cytochrome c oxidase subunit I from diverse metazoan invertebrates. Molecular Marine Biology and Biotechnology 3: 294-299.

Fontoura P., Bartels P.J., Jørgensen A., Kristensen R.M. \& Hansen J.G. 2017. A dichotomous key to the genera of the marine heterotardigrades (Tardigrada). Zootaxa 4294 (1): 1-45.

https://doi.org/10.11646/zootaxa.4294.1.1

Gąsiorek P., Stec D., Morek W., Zawierucha K., Kaczmarek Ł., Lachowska-Cierlik D. \& Michalczyk Ł. 2016. An integrative revision of Mesocrista Pilato, 1987 (Tardigrada: Eutardigrada: Hypsibiidae). Journal of Natural History 50: 2803-2828. https://doi.org/10.1080/00222933.2016.1234654

Gąsiorek P., Stec D., Zawierucha Z., Kristensen R.M. \& Michalczyk Ł. 2018. Revision of Testechiniscus Kristensen, 1987 (Heterotardigrada: Echiniscidae) refutes the polar-temperate distribution of the genus. Zootaxa 4472 (2): 261-297. https://doi.org/10.11646/zootaxa.4472.2.3

Giribet G., Carranza S., Baguña J., Riutort M. \& Ribera C. 1996. First molecular evidence for the existence of a Tardigrada + Arthropoda clade. Molecular Biology and Evolution 13: 76-84.

https://doi.org/10.1093/oxfordjournals.molbev.a025573 
STEC D. et al., Two new Macrobiotidae species from Greenland

Grøngaard A., Møbjerg Kristensen N. \& Petersen M.K. 1990. Tardigradfaunaen på Disko. In: Kristensen R.M. (ed.) Feltkursus i Arktisk Biologi, Godhavn 1990: 155--180. Zoological Museum, Copenhagen.

Guidetti R. \& Bertolani R. 2005. Tardigrade taxonomy: an updated check list of the taxa and a list of characters for their identification. Zootaxa 845: 1-46. https://doi.org/10.11646/zootaxa.845.1.1

Guidetti R., Gandolfi A., Rossi V. \& Bertolani R. 2005. Phylogenetic analysis of Macrobiotidae (Eutardigrada, Parachela): a combined morphological and molecular approach. Zoologica Scripta 34: 235-244. https://doi.org/10.1111/j.1463-6409.2005.00193.x

Guidetti R., Peluffo J.R., Rocha A.M., Cesari M. \& Moly de Peluffo M.C. 2013. The morphological and molecular analyses of a new South American urban tardigrade offer new insights on the biological meaning of the Macrobiotus hufelandi group of species (Tardigrada: Macrobiotidae). Journal of Natural History 47 (37-38): 2409-2426. https://doi.org/10.1080/00222933.2013.800610

Guidetti R., Rebecchi L., Bertolani R., Jönsson K.I., Kristensen R.M. \& Cesari M. 2016. Morphological and molecular analyses on Richtersius (Eutardigrada) diversity reveal its new systematic position and lead to the establishment of a new genus and a new family within Macrobiotoidea. Zoological Journal of the Linnean Society 178 (4): 834-845. https://doi.org/10.1111/zoj.12428

Guidetti R., Cesari M., Bertolani R., Altiero T. \& Rebecchi L. 2019. High diversity in species, reproductive modes and distribution within the Paramacrobiotus richtersi complex (Eutardigrada, Macrobiotidae). Zoological Letters 5: e1. http://dx.doi.org/10.1186/s40851-018-0113-z

Guil N. \& Giribet G. 2012. A comprehensive molecular phylogeny of tardigrades - adding genes and taxa to a poorly resolved phylum-level phylogeny. Cladistics 28 (1): 21-49.

https://doi.org/10.1111/j.1096-0031.2011.00364.x

Guil N., Guidetti R. \& Machordom A. 2007. Observations on the "tenuis group" (Eutardigrada, Macrobiotidae) and description of a new Macrobiotus species. Journal of Natural History 41 (41-44): 2741-2755. https://doi.org/10.1080/00222930701742637

Guil N., Jørgensen A. \& Kristensen R. 2019. An upgraded comprehensive multilocus phylogeny of the Tardigrada tree of life. Zoologica Scripta 48 (1): 120-137. https://doi.org/10.1111/zsc.12321

Hall T.A. 1999. BioEdit: a user-friendly biological sequence alignment editor and analysis program for Windows 95/98/NT. Nucleic Acids Symposium Series 41: 95-98.

Jørgensen A., Kristensen R.M. \& Møbjerg N. 2018. Phylogeny and integrative taxonomy of Tardigrada. In: Schill R.O. (ed.) Water Bears: The Biology of Tardigrades: 95-114. Springer, Stuttgart. https://doi.org/10.1007/978-3-319-95702-9_3

Kaczmarek Ł. \& Michalczyk Ł. 2017. The Macrobiotus hufelandi (Tardigrada) group revisited. Zootaxa 4363: 101-123. https://doi.org/10.11646/zootaxa.4363.1.4

Kaczmarek Ł., Cytan J., Zawierucha K., Diduszko D. \& Michalczyk Ł. 2014. Tardigrades from Peru (South America), with descriptions of three new species of Parachela. Zootaxa 3790: 357-379. https://doi.org/10.11646/zootaxa.3790.2.5

Kaczmarek Ł., Michalczyk Ł. \& McInnes S.J. 2016. Annotated zoogeography of non-marine Tardigrada. Part III: North America and Greenland. Zootaxa 4203: 1-249. https://doi.org/10.11646/zootaxa.4203.1.1

Katoh K. \& Toh H. 2008. Recent developments in the MAFFT multiple sequence alignment program. Briefings in Bioinformatics 9: 286-298. https://doi.org/10.1093/bib/bbn013

Katoh K., Misawa K., Kuma K. \& Miyata T. 2002. MAFFT: a novel method for rapid multiple sequence alignment based on fast Fourier transform. Nucleic Acids Research 30: 3059-66.

https://doi.org/10.1093/nar/gkf436 
Kumar S., Stecher G. \& Tamura K. 2016. MEGA7: Molecular Evolutionary Genetics Analysis version 7.0 for bigger datasets. Molecular Biology and Evolution 33: 1870-1874.

https://doi.org/10.1093/molbev/msw054

Manicardi G.C. 1989. Two new species of soil moss eutardigrades (Tardigrada) from Canada. Canadian Journal of Zoology 67: 2282-2285. https://doi.org/10.1139/z89-321

Maucci W. 1983. Sulla presenza in Italia di Cornechiniscus holmeni (Petersen, 1951), e descrizione di Macrobiotus hyperonyx sp. nov. Bollettino del Museo civico di Storia naturale di Verona 9: 175-179.

Maucci W. 1988. Tardigradi della Mongolia Esterna, con descrizione di Macrobiotus mongolicus sp. nov. Bollettino del Museo civico di Storia naturale di Verona 14: 339-349.

Maucci W. 1996. Tardigrada of the Arctic tundra with descriptions of two new species. Zoological Journal of the Linnean Society 116: 185-204. https://doi.org/10.1111/j.1096-3642.1996.tb02343.x

Michalczyk Ł. \& Kaczmarek Ł. 2003. A description of the new tardigrade Macrobiotus reinhardti (Eutardigrada, Macrobiotidae, harmsworthi group) with some remarks on the oral cavity armature within the genus Macrobiotus Schultze. Zootaxa 331: 1-24. https://doi.org/10.11646/zootaxa.331.1.1

Michalczyk Ł. \& Kaczmarek Ł. 2013. The Tardigrada Register: a comprehensive online data repository for tardigrade taxonomy. Journal of Limnology 72: 175-181. https://doi.org/10.4081/jlimnol.2013.s1.e22

Michalczyk Ł., Wełnicz W., Frohme M. \& Kaczmarek Ł. 2012. Redescriptions of three Milnesium Doyère, 1840 taxa (Tardigrada: Eutardigrada: Milnesiidae), including the nominal species for the genus. Zootaxa 3154: 1-20. https://doi.org/10.11646/zootaxa.3154.1.1

Mironov S.V., Dabert J., Dabert M. 2012. A new feather mite species of the genus Proctophyllodes Robin, 1877 (Astigmata: Proctophyllodidae) from the Long-tailed Tit Aegithalos caudatus (Passeriformes: Aegithalidae): morphological description with DNA barcode data. Zootaxa 3253: 5461. https://doi.org/10.11646/zootaxa.3253.1.2

Møbjerg N., Jørgensen A., Kristensen R.M. \& Neves R.C. 2018. Morphology and functional anatomy. In: Schill R.O. (ed.) Water Bears: The Biology of Tardigrades 57-94. Springer, Stuttgart.

https://doi.org/10.1007/978-3-319-95702-9_2

Morek W., Stec D., Gąsiorek P., Schill R.O., Kaczmarek Ł. \& Michalczyk Ł. 2016. An experimental test of eutardigrade preparation methods for light microscopy. Zoological Journal of the Linnean Society 178: 785-793. https://doi.org/10.1111/zoj.12457

Nelson D.R., Guidetti R. \& Rebecchi L. 2015. Phylum Tardgrada. In: Thorp and Covich's Freshwater Invertebrates: $347-380$, Academic Press, New York.

https://doi.org/10.1016/B978-0-12-385026-3.00017-6

Nowak B. \& Stec D. 2018. An integrative description of Macrobiotus hannae sp. nov. (Tardigrada: Eutardigrada: Macrobiotidae: hufelandi group) from Poland. Turkish Journal of Zoology 42: 269-286. https://doi.org/10.3906/zoo-1712-31

Pilato G. 1981. Analisi di nuovi caratteri nello studio degli Eutardigradi. Animalia 8: 51-57.

Roszkowska M., Ostrowska M., Stec D., Janko K. \& Kaczmarek Ł. 2017. Macrobiotus polypiformis sp. nov., a new tardigrade (Macrobiotidae; hufelandi group) from the Ecuadorian Pacific coast, with remarks on the claw abnormalities in eutardigrades. European Journal of Taxonomy 327: 1-19. https://doi.org/10.5852/ejt.2017.327

Schill R.O., Forster F., Dandekar T. \& Wolf N. 2010. Using compensatory base change analysis of internal transcribed spacer 2 secondary structures to identify three new species in Paramacrobiotus (Tardigrada). Organisms Diversity \& Evolution 10 (4): 287-296. https://doi.org/10.1007/s13127-010-0025-z 
STEC D. et al., Two new Macrobiotidae species from Greenland

Stec D. 2019. Mesobiotus datanlanicus sp. nov., a new tardigrade species (Macrobiotidae: Mesobiotus harmsworthi group) from Lâm Đồng Province in Vietnam. Zootaxa 4679 (1): 164-180.

https://doi.org/10.11646/zootaxa.4679.1.10

Stec D., Smolak R., Kaczmarek Ł. \& Michalczyk Ł. 2015. An integrative description of Macrobiotus paulinae sp. nov. (Tardigrada: Eutardigrada: Macrobiotidae: hufelandi group) from Kenya. Zootaxa 4052: 501-526. https://doi.org/10.11646/zootaxa.4052.5.1

Stec D., Gąsiorek P., Morek W., Kosztyła P., Zawierucha K., Michno K., Kaczmarek Ł., Prokop Z.M. \& Michalczyk Ł. 2016. Estimating optimal sample size for tardigrade morphometry. Zoological Journal of the Linnean Society 178: 776-784. https://doi.org/10.1111/zoj.12404

Stec D., Zawierucha K. \& Michalczyk Ł. 2017a. An integrative description of Ramazzottius subanomalus (Biserov, 1985) (Tardigrada) from Poland. Zootaxa 4300 (3): 403-420.

https://doi.org/10.11646/zootaxa.4300.3.4

Stec D., Morek W., Gąsiorek P., Blagden B. \& Michalczyk Ł. 2017b. Description of Macrobiotus scoticus sp. nov. (Tardigrada: Macrobiotidae: hufelandi group) from Scotland by means of integrative taxonomy. Annales Zoologici 67: 181-197. https://doi.org/10.3161/00034541ANZ2017.67.2.001

Stec D., Morek W., Gąsiorek P. \& Michalczyk Ł. 2018a. Unmasking hidden species diversity within the Ramazzottius oberhaeuseri complex, with an integrative redescription of the nominal species for the family Ramazzottiidae (Tardigrada: Eutardigrada: Parachela). Systematics and Biodiversity 16 (4): 357-376. https://doi.org/10.1080/14772000.2018.1424267

Stec D., Krzywański Ł. \& Michalczyk Ł. 2018b. Integrative description of Macrobiotus canaricus sp. nov. with notes on M. recens (Eutardigrada: Macrobiotidae). European Journal of Taxonomy 452: 1-36. https://doi.org/10.5852/ejt.2018.452

Stec D., Kristensen R.M. \& Michalczyk Ł. 2018c. Integrative taxonomy identifies Macrobiotus papei, a new tardigrade species of the Macrobiotus hufelandi complex (Eutardigrada: Macrobiotidae) from the Udzungwa Mountains National Park (Tanzania). Zootaxa 4446: 273-291. https://doi.org/10.11646/zootaxa.4446.2.7

Stec D., Arakawa K. \& Michalczyk Ł. 2018d. An integrative description of Macrobiotus shonaicus sp. nov. (Tardigrada: Macrobiotidae) from Japan with notes on its phylogenetic position within the hufelandi group. PLoS ONE 13: e0192210. https://doi.org/10.1371/journal.pone.0192210

Stec D., Krzywański Ł., Zawierucha K. \& Michalczyk Ł. 2020. Untangling systematics of the Paramacrobiotus areolatus species complex by an integrative redescription of the nominal species for the group, with multilocus phylogeny and species delineation within the genus Paramacrobiotus. Zoological Journal of the Linnean Society. https://doi.org/10.1093/zoolinnean/zlz163

Sutcliffe A.J. \& Blake W. Jr. 2000. Biological activity on a decaying caribou antler at Cape Herschel, Ellesmere Island, Nunavut, High Arctic Canada. Polar Record 36 (198): 233-246. https://doi.org/10.1017/S0032247400016491

Tumanov D.V. 2007. Three new species of Macrobiotus (Eutardigrada, Macrobiotidae, tenuis-group) from Tien Shan (Kirghizia) and Spitsbergen. Journal of Limnology 66: 40-48.

https://doi.org/10.4081/jlimnol.2007.s1.40

Wełnicz W., Grohme M.A., Kaczmarek Ł., Schill R.O. \& Frohme M. 2011. ITS-2 and 18S rRNA data from Macrobiotus polonicus and Milnesium tardigradum (Eutardigrada, Tardigrada). Journal of Zoological SystematicsandEvolutionaryResearch49(S1):34-39.https://doi.org/10.1111/j.1439-0469.2010.00595.x 
Zawierucha K., Coulson J., Michalczyk Ł. \& Kaczmarek Ł. 2013. Current knowledge on the Tardigrada of Svalbard with the first records of water bears from Nordaustlandet (High Arctic). Polar Research 32: e20886. https://doi.org/10.3402/polar.v32i0.20886

Zawierucha K., Kolicka M. \& Kaczmarek Ł. 2016a. Re-description of the Arctic tardigrade Tenuibiotus voronkovi (Tumanov, 2007) (Eutardigrada; Macrobiotidea), with the first molecular data for the genus. Zootaxa 4196 (4): 498-510. https://doi.org/10.11646/zootaxa.4196.4.2

Zawierucha K., Zmudczyńska-Skarbek K., Kaczmarek Ł. \& Wojczulanis-Jakubas K. 2016b. The influence of a seabird colony on abundance and species composition of water bears (Tardigrada) in Hornsund (Spitsbergen, Arctic). Polar Biology 39: 713-723. https://doi.org/10.1007/s00300-015-1827-4

Zeller C. 2010. Untersuchung der Phylogenie von Tardigraden anhand der Genabschnitte 18S rDNA und Cytochrom c Oxidase Untereinheit 1 (COX I). MSc Thesis, Technische Hochschule Wildau, Germany.

Manuscript received: 13 September 2019

Manuscript accepted: 8 November 2019

Published on: 12 March 2020

Topic editor: Rudy Jocqué

Desk editor: Marianne Salaün

Printed versions of all papers are also deposited in the libraries of the institutes that are members of the EJT consortium: Muséum national d'histoire naturelle, Paris, France; Botanic Garden Meise, Belgium; Royal Museum for Central Africa, Tervuren, Belgium; Royal Belgian Institute of Natural Sciences, Brussels, Belgium; Natural History Museum of Denmark, Copenhagen, Denmark; Naturalis Biodiversity Center, Leiden, the Netherlands; Museo Nacional de Ciencias Naturales-CSIC, Madrid, Spain; Real Jardín Botánico de Madrid CSIC, Spain; Zoological Research Museum Alexander Koenig, Bonn, Germany; National Museum, Prague, Czech Republic. 
STEC D. et al., Two new Macrobiotidae species from Greenland

Appendix 1. Sequences of species from Macrobiotus hufelandi group used for molecular comparisons in this study. Underlined GenBank accession numbers indicate type or neotype sequences.

\begin{tabular}{|c|c|c|c|}
\hline $\begin{array}{l}\text { DNA } \\
\text { marker }\end{array}$ & Species & Accession number & Source \\
\hline \multirow[t]{18}{*}{ 18S rRNA } & M. canaricus Stec et al., 2018 & MH063925 & Stec et al. (2018b) \\
\hline & M. noongaris Coughlan \& Stec, 2019 & MK737069 & Coughlan \& Stec (2019) \\
\hline & M. kamilae Coughlan \& Stec, 2019 & MK737070 & Coughlan \& Stec (2019) \\
\hline & M. caelestis Coughlan et al., 2019 & MK737073 & Coughlan et al. (2019) \\
\hline & “M. hufelandi" Schultze, 1834 & GQ849024 & Giribet et al. (1996) \\
\hline & M. hufelandi group species & HQ604971, FJ435738-40 & $\begin{array}{l}\text { Bertolani et al. (2014), } \\
\text { Guil \& Giribet (2012) }\end{array}$ \\
\hline & M. hannae Nowak \& Stec, 2018 & MH063922 & Nowak \& Stec (2018) \\
\hline & $\begin{array}{l}\text { "M. joannae" Pilato \& Binda, } 1983 \\
(=\text { M. hannae Nowak \& Stec, 2018) }\end{array}$ & HQ604974-5 & Bertolani et al. (2014) \\
\hline & M. kristenseni Guidetti et al., 2013 & KC193577 & Guidetti et al. (2013) \\
\hline & M. macrocalix Bertolani \& Rebecchi, 1993 & HQ604976,MH063926 & Bertolani et al. (2014), \\
\hline & M. papei Stec et al., 2018 & MH063881 & Stec et al. (2018c) \\
\hline & M. paulinae Stec et al., 2015 & KT935502 & Stec et al. (2015) \\
\hline & M. polypiformis Roszkowska et al., 2017 & KX810008 & Roszkowska et al. (2017) \\
\hline & M. polonicus Pilato et al., 2003 & HM187580 & Wełnicz et al. (2011) \\
\hline & M. cf. recens Cuénot, 1932 & MH063927 & Stec et al. (2018b) \\
\hline & M. sapiens Binda \& Pilato, 1984 & DQ839601 & Bertolani et al. (2014) \\
\hline & M. scoticus Stec et al., 2017 & KY797265 & Stec et al. (2017b) \\
\hline & M. shonaicus Stec et al., 2018 & MG757132 & Stec et al. (2018d) \\
\hline \multirow[t]{13}{*}{ 28S rRNA } & M. canaricus Stec et al., 2018 & MH063934 & Stec et al. (2018b) \\
\hline & M. noongaris Coughlan \& Stec, 2019 & MK737063 & Coughlan \& Stec (2019) \\
\hline & M. kamilae Coughlan \& Stec, 2019 & MK737064 & Coughlan \& Stec (2019) \\
\hline & M. caelestis Coughlan et al., 2019 & MK737071 & Coughlan et al. (2019) \\
\hline & M. hannae Nowak \& Stec, 2018 & MH063924 & Nowak \& Stec (2018) \\
\hline & M. hufelandi group species & FJ435751, FJ435754-5 & Guil \& Giribet (2012) \\
\hline & M. macrocalix Bertolani \& Rebecchi, 1993 & MH063935 & Stec et al. (2018b) \\
\hline & M. papei Stec et al., 2018 & MH063880 & Stec et al. (2018c) \\
\hline & M. paulinae Stec et al., 2015 & KT935501 & Stec et al. (2015) \\
\hline & M. polypiformis Roszkowska et al., 2017 & KX810009 & Roszkowska et al. (2017) \\
\hline & M. cf. recens Cuénot, 1932 & MH063936 & Stec et al. (2018b) \\
\hline & M. scoticus Stec et al., 2017 & KY797266 & Stec et al. (2017b) \\
\hline & M. shonaicus Stec et al., 2018 & MG757133 & Stec et al. (2018d) \\
\hline \multirow[t]{9}{*}{ ITS-2 } & $\begin{array}{l}\text { M. canaricus Stec et al., } 2018 \\
\text { M. noongaris Coughlan \& Stec, } 2019\end{array}$ & $\begin{array}{l}\text { MH063928-30 } \\
\text { MK737065-6 }\end{array}$ & $\begin{array}{l}\text { Stec et al. (2018b) } \\
\text { Coughlan \& Stec (2019) }\end{array}$ \\
\hline & M. kamilae Coughlan \& Stec, 2019 & MK737067 & Coughlan \& Stec (2019) \\
\hline & M. caelestis Coughlan et al., 2019 & MK737072 & Coughlan et al. (2019) \\
\hline & M. hannae Nowak \& Stec, 2018 & MH063923 & Nowak \& Stec (2018) \\
\hline & M. macrocalix Bertolani \& Rebecchi, 1993 & MH063931 & Stec et al. (2018b) \\
\hline & M. papei Stec et al., 2018 & MH063921 & Stec et al. (2018c) \\
\hline & M. paulinae Stec et al., 2015 & KT935500 & Stec et al. (2015) \\
\hline & M. polonicus Pilato et al., 2003 & HM150647 & Wełnicz et al. (2011) \\
\hline & M. polypiformis Roszkowska et al., 2017 & KX810010 & Roszkowska et al. (2017) \\
\hline
\end{tabular}




\begin{tabular}{|c|c|c|c|}
\hline $\begin{array}{l}\text { DNA } \\
\text { marker }\end{array}$ & Species & Accession number & Source \\
\hline & $\begin{array}{l}\text { M. cf. recens Cuénot, } 1932 \\
\text { M. sapiens Binda \& Pilato, } 1984\end{array}$ & $\begin{array}{l}\text { MH063932-3 } \\
\text { GQ403680 }\end{array}$ & $\begin{array}{l}\text { Stec et al. (2018b) } \\
\text { Schill et al. (2010) }\end{array}$ \\
\hline & $\begin{array}{l}\text { M. scoticus } \text { Stec et al., } 2017 \\
\text { M. shonaicus Stec et al., } 2018\end{array}$ & $\begin{array}{l}\text { KY797268 } \\
\text { MG757134-5 }\end{array}$ & $\begin{array}{l}\text { Stec et al. }(2017 \mathrm{~b}) \\
\text { Stec et al. }(2018 \mathrm{~d})\end{array}$ \\
\hline \multirow[t]{17}{*}{ COI } & $\begin{array}{l}\text { M. canaricus Stec et al., } 2018 \\
\text { M. noongaris Coughlan \& Stec, } 2019\end{array}$ & $\begin{array}{l}\text { MH057765-6 } \\
\text { MK737919 }\end{array}$ & $\begin{array}{l}\text { Stec et al. (2018b) } \\
\text { Coughlan \& Stec (2019) }\end{array}$ \\
\hline & M. kamilae Coughlan \& Stec, 2019 & MK737920-1 & Coughlan \& Stec (2019) \\
\hline & M. caelestis Coughlan et al., 2019 & MK737922 & Coughlan et al. (2019) \\
\hline & M. hannae Nowak \& Stec, 2018 & MH057764 & Nowak \& Stec (2018) \\
\hline & M.cf. hufelandi, Schultze, 1834 & HQ876589-94, HQ876596 & Bertolani et al. (2011a) \\
\hline & M. hufelandi, Schultze, 1834 & HQ876584, HQ876586-8 & Bertolani et al. (2011a) \\
\hline & M. kristenseni Guidetti et al., 2013 & KC193575-6 & Guidetti et al. (2013) \\
\hline & M. macrocalix Bertolani \& Rebecchi, 1993 & $\begin{array}{l}\text { FJ176203-7, FJ176208- } \\
\text { 17,HQ876571,MH057767 }\end{array}$ & $\begin{array}{l}\text { Cesari et al. (2009), } \\
\text { Bertolani et al. (2011a) } \\
\text { Stec et al. (2018b) }\end{array}$ \\
\hline & M. papei Stec et al., 2018 & MH057763 & Stec et al. (2018c) \\
\hline & M. paulinae Stec et al., 2015 & KT951668 & Stec et al. (2015) \\
\hline & M. polypiformis Roszkowska et al., 2017 & KX810011-2 & Roszkowska et al. (2017) \\
\hline & M. cf. recens Cuénot, 1932 & MH057768-9 & Stec et al. (2018b) \\
\hline & M. sandrae Bertolani \& Rebecchi, 1993 & $\begin{array}{c}\text { HQ876566-67, HQ876569- } \\
70, \text { HQ876572-83 }\end{array}$ & Bertolani et al. (2011a) \\
\hline & M. scoticus Stec et al., 2017 & KY797267 & Stec et al. (2017b) \\
\hline & M. shonaicus Stec et al., 2018 & MG757136-7 & Stec et al. (2018d) \\
\hline & M. terminalis Bertolani \& Rebecchi, 1993 & JN673960,AY598775 & $\begin{array}{l}\text { Cesari et al. (2011), } \\
\text { Guidetti et al. (2005) }\end{array}$ \\
\hline & M. vladimiri Bertolani et al., 2011 & $\begin{array}{c}\text { HM136931-2, } \\
\text { HM136933-4, HQ876568 }\end{array}$ & $\begin{array}{l}\text { Bertolani et al. (2011a, } \\
\text { 2011b) }\end{array}$ \\
\hline
\end{tabular}

\section{Supplementary files:}

SM.01. Raw morphometric data underling the description of Macrobiotus engbergi sp. nov. https://europeanjournaloftaxonomy.eu/index.php/ejt/article/downloadSuppFile/879/93

SM.02. Raw morphometric data underling the description of Tenuibiotus zandrae sp. nov. https://europeanjournaloftaxonomy.eu/index.php/ejt/article/downloadSuppFile/879/95

SM.03. Uncorrected pairwise distances.

https:/europeanjournaloftaxonomy.eu/index.php/ejt/article/downloadSuppFile/879/97 